\title{
Growth in ruminants: a comparison of some mechanistic models
}

\author{
Ph Schmidely \\ Institut National Agronomique Paris-Grignon, Départment des Sciences Animales, 16 rue Claude Bernard, \\ 75231 Paris Cedex 05. France
}

Improving efficiency of food conversion into animal products by ruminants is an important goal of fundamental and applied research. During the last two decades, much knowledge on digestion and metabolism, and to a lesser extent, on hormonal regulation of nutrient partitioning have been obtained at different levels of aggregation, ranging from the animal level to the cellular one. Moreover, new concerns have emerged, dealing with problems of environment and animal welfare.

Two types of models of growing ruminants exist. Historically, they are first empirical models, which aimed to predict feed requirement from animal performances (ADG and $B W$ ) for on-farm situations. Despite their useful application in practical average conditions, these models are limited by the small sets of experimental data on which they are built. Moreover, they work at an only one level of aggregation (generally the animal level). Currently, the need for understanding and prediction of the animal responses (quantity of products, quality, efficiency, welfare...) in relation to the variations of feeding can not be fulfilled only by this approach. Mechanistic models based on biochemical principles provide researchers the way to build theoretical and conceptual frameworks, which could help them to integrate new research results (particularly on the underlying mechanisms regulating growth and partition of nutrients) and to indicate the areas of future researches that are needed.

Consequently, models of growing ruminants can be divided into 2 classes: extension models and research models. In the scope of this review, we will consider the second type, because it is probably the one which can be used to increase our comprehension of ruminant metabolism. It will also allow the design of more appropriate experiments in order to alter their metabolism during growth, this later aspect concerns particularly the partition of nutrients between lean and adipose tissues.

\section{Relationships between the degree of aggregation of the model and its objectives.}

For comparative purposes, we have reviewed the following mechanistic models of the growing ruminants: Gill et al, 1984 (GILL1), Oltjen et al, 1986a,b (OLTJ); France et al, 1987 (FRAN); Di Marco et al, 1989, and Di Marco and Baldwin, 1989 (MARC), Gill et al, 1989a,b (GILL2); Sainz and Wolff, 1990a,b (SAWO). In addition to differences in animal reference (growing lamb for GILL1, GILL2 and SAWO models, growing steer for the others), these models also differ in their objectives, their levels of aggregation, the number of compartments they contain, the nutrients and fluxes that are considered, their approach of regulation.

\section{Objectives of the models}

The level of aggregation of the models depends on their objectives. The main objectives (classified by descending level of aggregation) are:

a) to simulate empty body weight and body composition for different ranges of time (all models);

b) to take into account the genetic background (frame size, OLTJ);

c) to simulate the impact of nutritional history and nutritional modulation (underfeeding, overfeeding, compensatory growth) on growth and body composition (OLTJ, MARC);

d) to simulate some aspects of the energy or nitrogen metabolism (GILL1 and GILL2, MARC), and/or the efficiency of utilization of absorbed nutrients (GILL1, MARC);

e) to evaluate hypotheses regarding the modes of action of growth promoters on the partition of nutrients (SAWO);

Objectives a,b,c and to a lesser extent $\mathbf{e}$ represent models reflecting priority of certain organs or tissues for utilization of nutrients (i.e. 
homeorhesis, Bauman and Currie, 1980), according to the classical theories of growth (Brody, 1945). Models d place more emphasis on homeostasis (i.e. constancy of certain endogenous characteristics, particularly concerning energy homeostasis).

\section{Description of the models: what are the driving forces?}

In the OLTJ model (fig 1), the driving force of the model is reflecting the underlying processes regulating growth, i.e. hyperplasia (cells number or DNA synthesis) and hypertrophia (cells size or protein (Pro) accretion). Indeed, it has been shown that, as muscle grows, there is a simultaneous increase in DNA content and in the Pro/DNA content (Burleigh, 1980). The model predicts net gain of DNA and Pro, in the empty body (EB) of a reference animal where simultaneous collection of DNA and Pro content in the whole body are necessited. The Pro submodel drives the gain of fat (AT), which is calculated after accounting for the net energy needs for maintenance and Pro accretion. Consequently, the OLTJ model includes a limited number of compartments (DNA, Pro, AT), the more mechanistic part of the model being limited to the DNA and Pro compartments. No attempt is made to take into account growth limitation by dietary protein. The reference animal is a British breed steer, and its growth and body composition are simulated on $300 \mathrm{~d}$ between 200 and $500 \mathrm{~d}$ of age.

The MARC model (fig 2) aims to quantity the relationship between dynamic accretion of DNA, Pro and fat, and to connect them with a metabolic submodel, in order to study energetic requirements for body accretion. As in OLTJ model, driving force was related to DNA pools. When compared with OLTJ model, Pro and DNA pools were defined as body (hide, skeleton, muscle, brain, i.e., tissues with low turn-over) or viscera, (blood, liver, digestive tract, i.e., tissues with high turn-over). The model predicts Pro and DNA data in tissues of growing cattle (Di Marco et al, 1987). The AT compartment is described in a more mechanistic way than for OLTJ model, taking into account lipogenesis from acetate $(A C)$ and fatty acids (FA), and lypolysis. To these 5 compartments are added four other state variables (amino-acids (AA), AC, FA and glucose (Glu) in the plasma) and 11 intermediary zero pools (for which production equals utilization). These zero pools are included for energetic purposes (ATP synthesis and utilization) or stoichiometric reasons. Animal characteristics and period of simulation are similar to the steer of OLTJ model.

The GILL1 model (fig 3) describes the metabolism of absorbed nutrients in a growing sheep on a $2 \mathrm{~d}$ period. Nutrients are partitioned between synthetic (fat and protein deposition), oxidative or intermediate reactions (ATP and

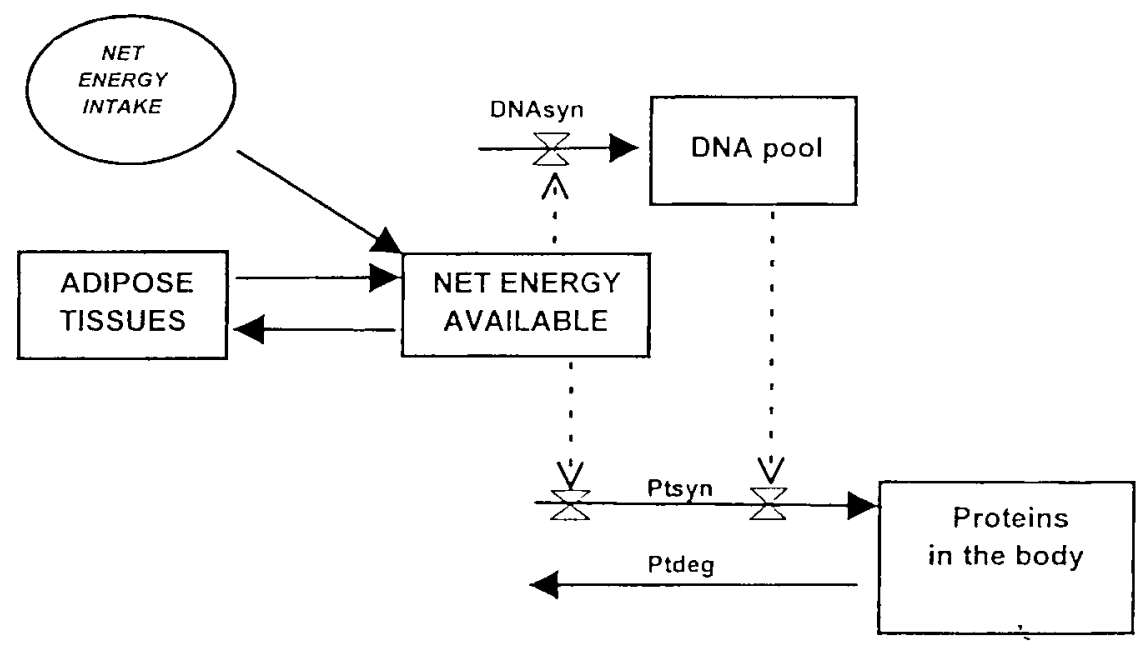

Figure 1. Diagram of the model of Oltjen et al (1986). 


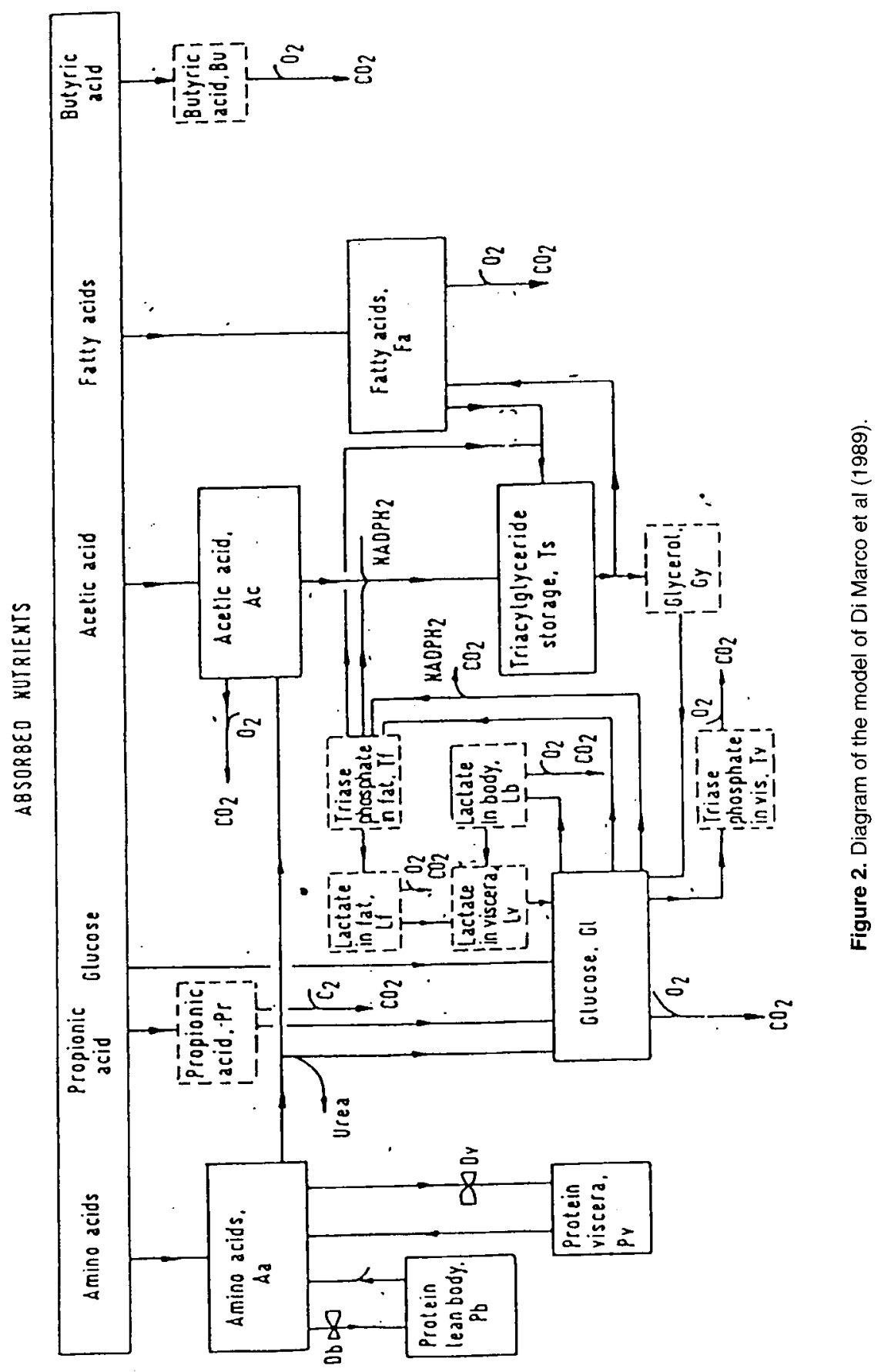




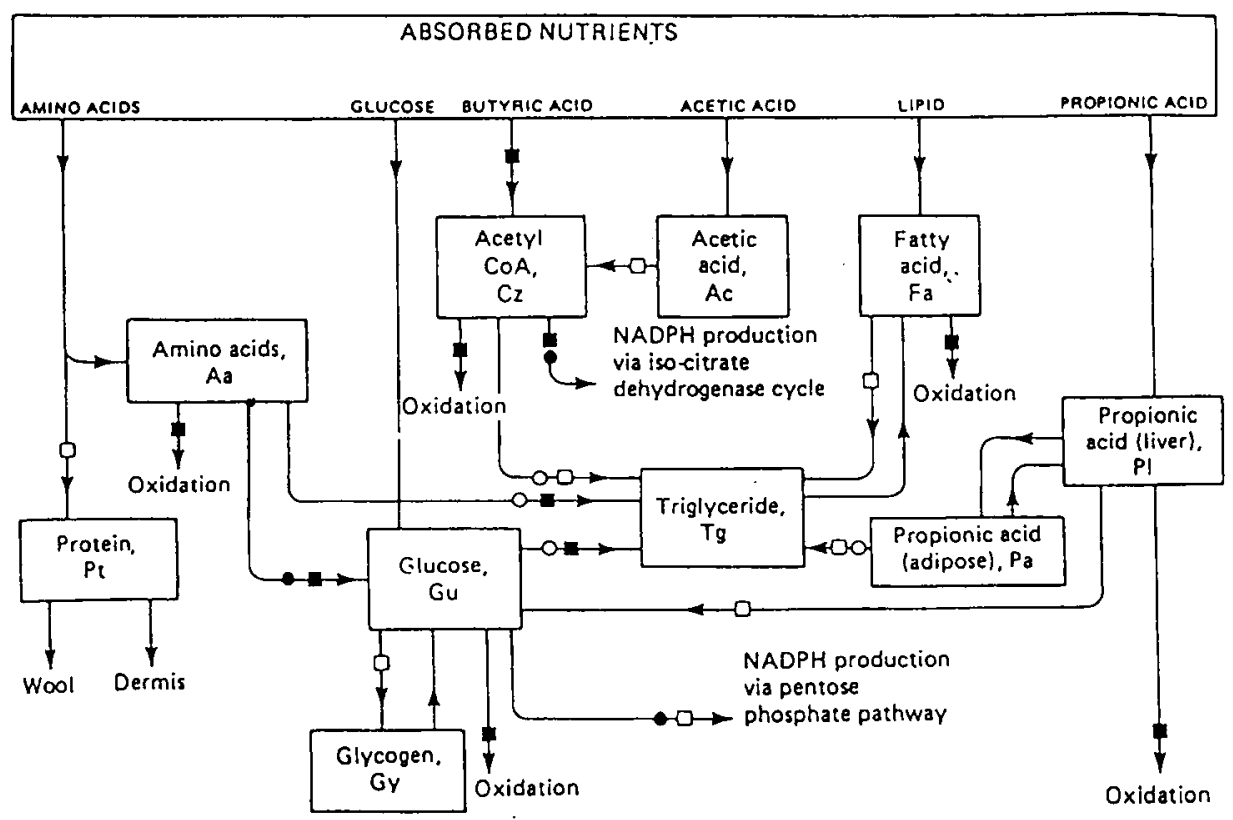

Model for the efficiency of utilization of absorbed energy. Only the principal substrates and products are shown; carbon dioxide $(C x)$, oxygen $(O x)$ and urea (Ur) are also involved in many of these reactions. ATP (At) and NADPH (NP) are two important variables not shown above. The reactions are coded: (更). Al-producing; ( $\square$ ), At-requiring; (O), Np-producing; (O) Np-requiring. Maintenance is not shown above, but is a drain on the At pool.

Figure 3. Diagram of the model of Gill et al (1984).

NADPH production). A total of 12 compartments are used, in order to simulate energy metabolism in growing sheep fed forage and concentrate diets, and in order to explain differences in efficiency of nutrient utilization in relation with the glucogenic potential of the diet (Mac Rae and Lobley, 1982). Consequently, the model particularly focuses on propionate $(\mathrm{Pr})$ and Glu metabolism, ATP and NADPH production, and finally lipid deposition, and its driving force is constituted by the absorbed nutrients inputs.

The FRAN model (fig 4) describes $\mathrm{C}$ and $\mathrm{N}$ fluxes in growing steers and is a simplification of the GILL1 model with 6 compartments: ash, lipid, and Pro in EB, and acetyl-CoA equivalents (representing source of $C_{2}$ units and energy), Glu equivalents and AA. Growth and body composition are simulated on periods between 70 and $100 \mathrm{~d}$, in response to modified nutrient inputs.
The SAWO model (fig 5) is derived from GILL1 for energetic submodel and from MARC for the accretion of DNA, Pro and AT. Consequently, the driving force of the model is represented by DNA accretion, which is defined by an empirical equation. As their aim is to test current hypothesis on the modes of action of some growth promotants (growth hormone, anabolic steroids, and $\beta$-agonists) on body composition, a model simulating the growth of a sheep between 20 and $40 \mathrm{~kg}$ of empty body weight is developed, with a more mechanistic approach of body fat and protein turnovers. Consequently, 4 Pro pools (carcass, viscera (abdominal and thoracic organs), wool, and other tissues), are associated with DNA accretion in these pools. Four others state variables (Glu, Ac, AA and lipids), and 7 zero pools ( $\mathrm{Pr}$, glycerol, triose phosphate, lactate, ATP and ADP) are included in the model.

The Gill2 model (fig 6) represents whole 


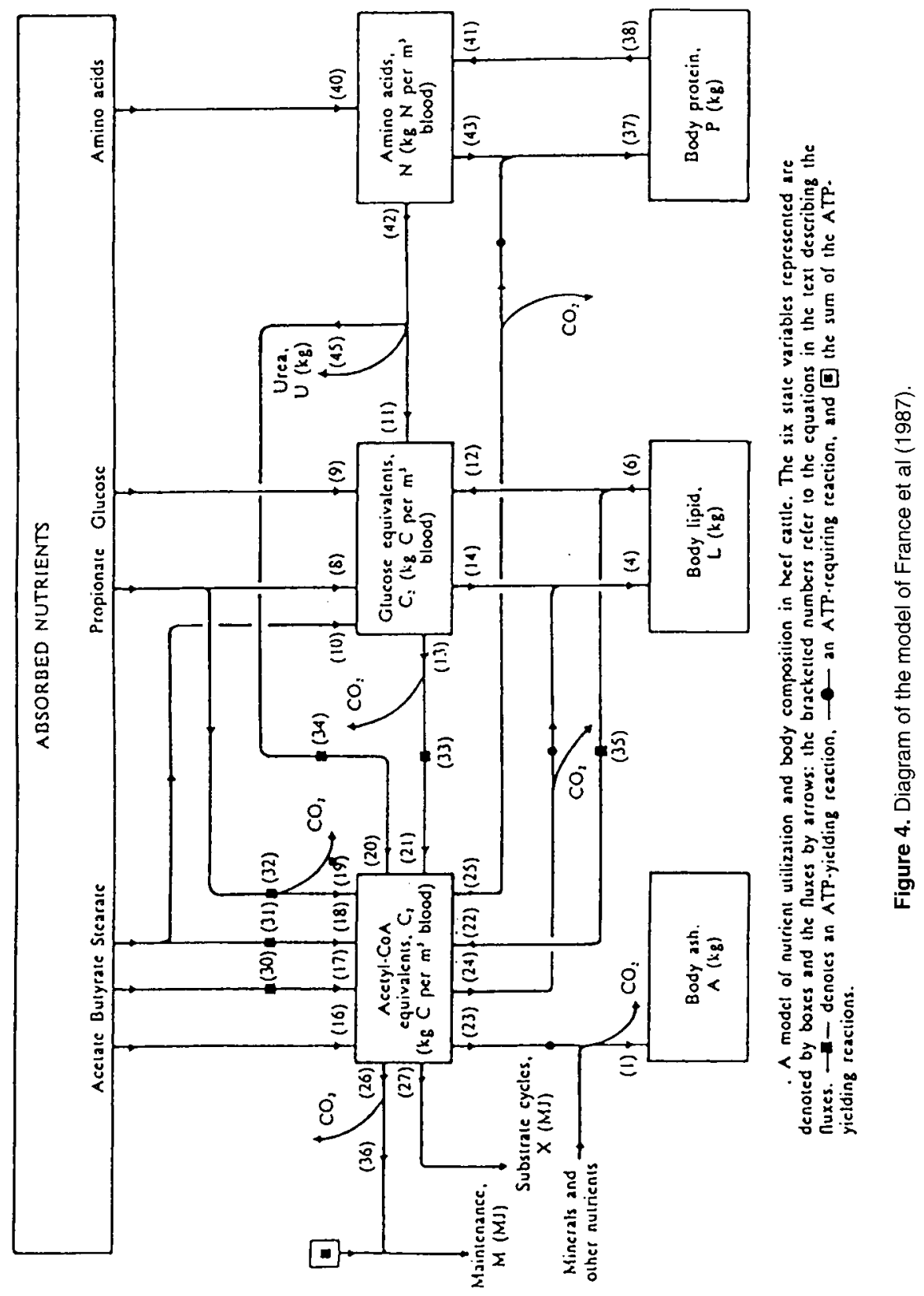




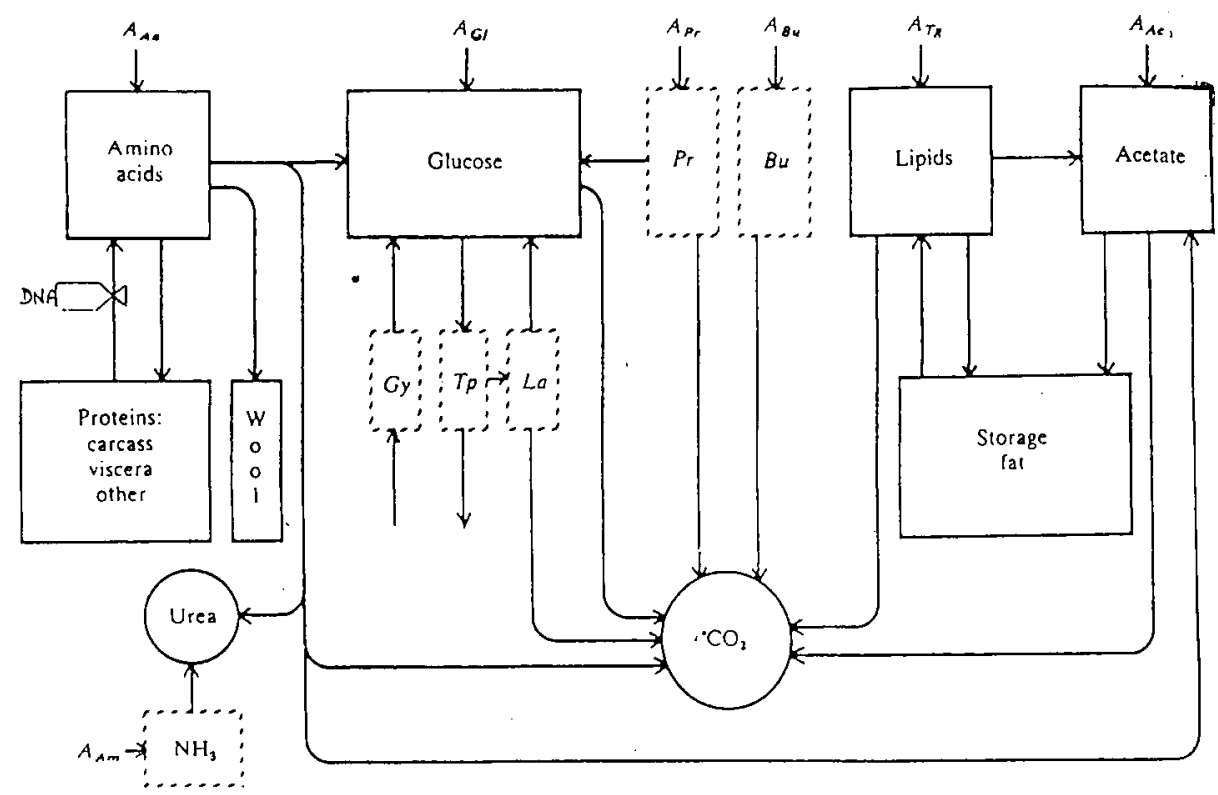

Figure 5. Diagram of the model of Sainz and Wolff (1990).

body protein synthesis and degradation in a growing lamb at two different growth rates, and it integrates knowledge of the cost expenditures (in terms of ATP) related to protein turnover and $\mathrm{Na}^{+}-\mathrm{K}^{+}$transports across the cell membranes. It includes 10 Pro tissues and AA-related pools, with the driving variable being $A A$ absorption through the gut wall, and digestible organic matter. The basic assumption is that ATP is non limiting for Pro synthesis (Pro metabolism is independent of energy status). Other assumptions are:

- inter-organ transfers of $A A$ in relation to nitrogen economy are not represented;

- the portion of AA flux from the blood into the cell that incurs an energy cost is assumed to equal the requirement for net accretion;

\section{The structure of the models: the main compartments and the regulation of the fluxes.}

According to concepts developed by Sauvant (1994), the organisms can be considered as systems, which consist of an operating subsystem (OS) and a regulating sub-system
(RS), which are interconnected, i.e. they exchange fluxes of matter or informations. The OS is represented by the compartments (pools size) and the fluxes of mass or energy in the model, whereas RS reflects short term (homeostasis) and long-term (homeorhesis) regulation. This classification is used here to describe the selected models of growing ruminants.

\section{Compartments}

Each compartment or body pool is represented by a state variable. The pool is described by its initial value, and the rate of change of quantity $(\delta S I Z E)$ by time units $(\delta t)$ in the pool :

$$
\delta S I Z E / d t=\text { Inputs }- \text { Outputs }
$$

\section{Main structural compartments involved}

Proteins and amino acids compartments: connection with nucleic acids (ADN) accretion

All models of growing ruminant include body Pro compartments as a major compartment, because Pro metabolism associated with skeletal development is the major determinant 


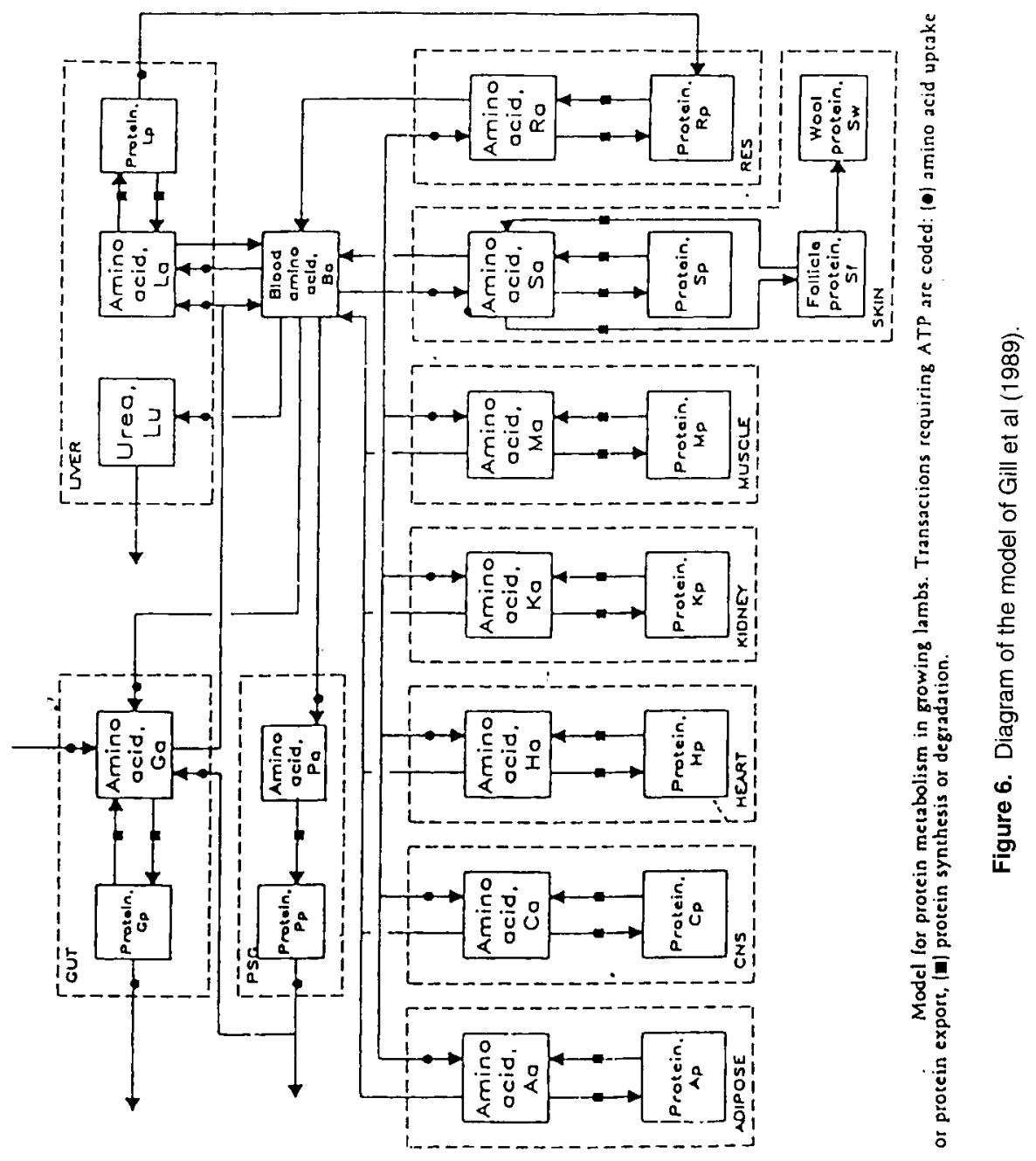




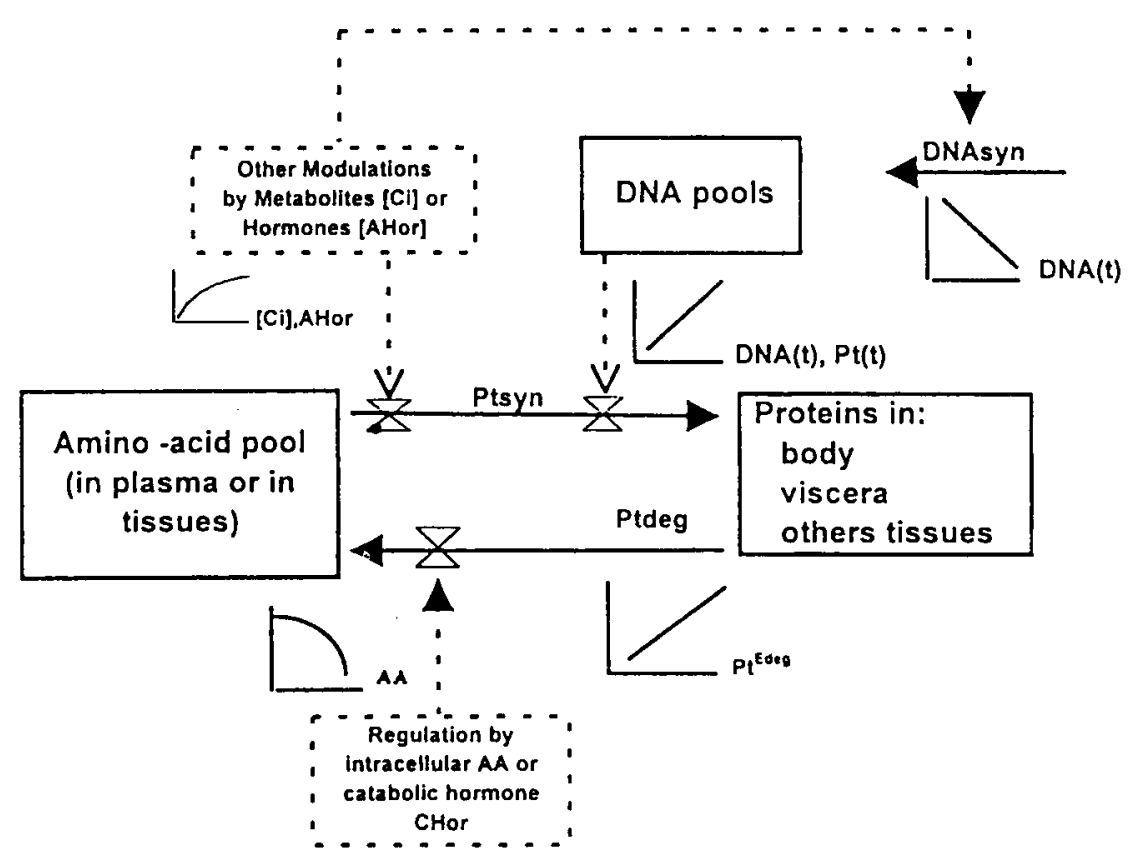

Figure 7. A general diagram of protein metabolism and connexion with ADN accretion in the growing ruminant.

of body growth (Lobley, 1986). The number of Pro pools varies with the level of aggregation of a given model: from 1 (total Pro in the EB for OLTJ et FRAN), 2 for MARC (body and viscera), 3 for GILL1 (body, wool and dermis), 4 for SAWO (body, viscera, wool, other tissues) and up to 12 for GILL2 (Gut, liver, pancreatic and salivary glands, skin, follicles and wool, adipose tissues, CNS, heart, kidney, muscle, skin, reticuloendothelial system). For each pool, Pro deposition (fig 7) is constituted by the balance between a synthetic transaction (proteosynthesis) and a catabolic one (proteolysis).

\section{-Proteosynthesis (Prosyn)}

The maximal rate of Prosyn in the GILL1 model is fitted empirically to metabolizable energy intake and to metabolic body weight (BW), according to Black and Griffiths (1975). The actual rate of protein accretion is set to the smaller value between maximal rate calculated above and maximal rate allowed by diet to which a biological value ( $B V=0.75$ ) is assigned.
In the Gill2 model, the protein synthesis in each tissue is related to the quantity of Pro in the tissue:

$$
\text { Prosyn }=\text { KProsyn } * \text { Pro }(t) * f[N U T i]
$$

where KProsyn is a constant (table I).

In the other models which are more mechanistic for Pro compartments, Prosyn is related to DNA pool size in this compartment (OLTJ, MARC, and SAWO models), according to concept of growth as described by Baldwin and Black (1979). Prosyn is expressed by the form (OLTJ and SAWO models):

$$
\begin{aligned}
& \text { Prosyn }=\text { KProsyn * ProEProsyn }(t) \text { * } \\
& \text { DNAEDNA }(t) * f[N U T i, \text { AHor }]
\end{aligned}
$$

(with ProEProsyn $(t)=1$ for OLTJ),

or (MARC model):

Prosyn $=$ KProsyn' * ProEProsyn $(\mathrm{t}) *[$ Promax

/ DNAmax - Pro $(t) / D N A(t)] * f[N U T i]$

where KProsyn and KProsyn' are constants, EProsyn and EDNA are constants (exponents 
Table I. Main values of constants of synthetic transactions (Prosyn) for the different protein (Pro) compartments involved in different mechanistic models of growing ruminant.

\begin{tabular}{|c|c|c|c|c|}
\hline \multirow[t]{2}{*}{ Model } & \multirow[t]{2}{*}{ Compartment } & \multirow[t]{2}{*}{ Independant variables } & \multicolumn{2}{|c|}{ Values of the constants } \\
\hline & & & KProsyn & ETgsyn \\
\hline OLTJ & Prob & DNAbEProsyn & $0.0472 \mathrm{~kg}$ Prob $/\left(\mathrm{g} D N A^{0.73 * d}\right)$ & 0.73 \\
\hline GILL2 1 & Prom & Prom & $0.39 \mathrm{mM} \mathrm{AA} /(\mathrm{g}$ Prom $/ \mathrm{d})$ & 1 \\
\hline GILL2 & Prol & Prol & $3.26 \mathrm{mM} \mathrm{AA} /(\mathrm{g}$ Prom $/ \mathrm{d})$ & 1 \\
\hline FRAN & Prob & $\operatorname{Prob}^{*}(1-($ Prob/Probmax $))$ & $0.190 \mathrm{~kg}$ Prob / (kg Prob * d) & 1 \\
\hline \multirow[t]{2}{*}{ MARC } & Proc & $\left.\operatorname{Proc} \operatorname{EProsyn}_{(\pi-P r o c / D N A c}\right)$ & $1.17 \mathrm{e}-4 \mathrm{~g}$ DNA / (M AA $\left.2.19{ }^{*} \mathrm{j}\right)$ & 2.19 \\
\hline & Prov & $\operatorname{Prov}$ EProsyn $(\pi$-Prov/DNAv) & & 0.80 \\
\hline \multirow[t]{4}{*}{ SAWO } & Proc & ProcEProsyn, DNAc & $21.7 \mathrm{M} \mathrm{AA} /\left(\mathrm{M} \mathrm{AA}^{0.682^{\star}} \mathrm{kg} \mathrm{DNA}{ }^{*} \mathrm{~d}\right)$ & 0.682 \\
\hline & Prov & ProvEProsyn, DNAv & $63.2 \mathrm{M} \mathrm{AA} /\left(\mathrm{M} \mathrm{AA}^{0.852^{\star}} \mathrm{kg} \mathrm{DNA}{ }^{*} \mathrm{~d}\right)$ & 0.852 \\
\hline & Proz & ProvEProsyn, DNAz & 33.8 M AA $\left(\mathrm{M} \mathrm{AA}^{0.882^{*}} \mathrm{~kg} \mathrm{DNA}{ }^{*} \mathrm{~d}\right)$ & 0.882 \\
\hline & Prow & ProvEProsyn, DNAz & $0.015 \mathrm{M} \mathrm{AA} /\left(\mathrm{M} \mathrm{AA}^{0.916^{*}} \mathrm{~kg} \mathrm{DNA}^{*} \mathrm{~d}\right)$ & d) 0.916 \\
\hline
\end{tabular}

1 Only 2 of the 10 Pro compartments of Gill 2 model are indicated.

Prob, Proc, Prom, Prov, Prow, and Proz = Protein in empty body, in carcass, in muscle, in viscera, in wool, and in other tissues. Probmax = maximal value of AA pool in mature reference animal. DNAb, DNAc, DNAv, DNAz = DNA in the body, in the carcass, in the viscera, and in other tissues, respectively. $M=$ mole, $A A$ amino acids. $\pi=$ Procmax/DNAcmax (MARC model).

The general expression of Prosyn is: Prosyn $=$ KProsyn * independant variables * $f($ AHor, Nuti).

with no dimension, table 1 , and Promax and DNAmax are values of Pro and DNA in the adult reference animal. The functions $f[N U T i$, AHor] or f[NUTi] are expressions taking eventually into account the hormonal status (anabolism) of the ruminant (AHor for SAWO and MARC models, see section «Partition of fluxes: hormonal regulation"), and(or) the fact that plasma availability of some nutrients (AA or others nutrients) may be limiting for Prosyn (see section «Regulation by the availability of nutrients").

In the FRAN model, Prosyn is not related to DNA accretion, because of a lack of experimental data relating DNA and Pro with age. Consequently, Prosyn was related to the factor Pro*(1-Pro) (logistical model):

Prosyn $=$ KProsyn $*$ ProEProsyn $(t) *[1-$

$\left.\left(\text { Pro }(\mathrm{t}) / \text { Promax }^{E}\right)^{\text {syn }}\right] * \mathrm{f}[\mathrm{NUTi}]$

where Promax is assigned to $200 \mathrm{~kg}$ for the reference animal (Friesian cattle of $1000 \mathrm{~kg}$ ).

Nutritional control (nutrients availability f[NUTi] for synthetic processes) will be examined below (see section "Regulation by the availability of nutrients").

\section{-Proteolysis}

In all models studied except for the GILL1 model where no Prodeg is considered because of the short period on which the model is tested (2d), Prodeg in a given compartment is a function of the size of actual protein pool Pro(t), according to the form (mass action law):

$$
\text { Prodeg }=\text { KProdeg } * \text { ProEProDeg }(\mathrm{t}) * \mathrm{f}[\mathrm{CHor}]
$$

where KProdeg is equivalent to the fractional degradation rate (table II), EProdeg (exponent with no dimension), $f[\mathrm{CHor}$ represents the effect of a theoretical catabolic hormone (CHor, with no dimension) on proteolysis (see section «Partition of fluxes: hormonal regulation"). This concept of Pro turn-over agrees with the hypothesis on proteolysis elaborated by Schimke (1969) and Garlick (1980).

-DNA synthesis

Daily accretion of DNA (DNAsyn) in each DNA compartment related to a Pro compartment, is defined by a modified expression of the logistic equation (OLTJ and SAWO models):

$$
\begin{aligned}
& \text { DNAsyn }=\text { KDNAsyn * [DNAmax }- \text { DNA(t)] * } \\
& \text { f[NUTi, AHor] }
\end{aligned}
$$

or by (MARC model):

$$
\begin{aligned}
& \text { DNAsyn = KDNAsyn' * ProEPro * } 1 \text { 1-DNA(t) } \\
& \text { / DNAmax } \left.{ }^{*} \text { f[NUTi }\right]
\end{aligned}
$$

where all parameters are defined as above Equations 6 and 7 are based on the relationship between DNA and age, and on the knowledge of an estimate of DNAmax for the animal taken as a reference. 
Table II. Main values of constants of catabolic transactions (Prodeg) for the different protein (Pro) compartments involved in different mechanistic models of growing ruminant.

\begin{tabular}{|c|c|c|}
\hline Model & Compartment & Independant variables \\
\hline OLTJ & Prob & ProbEProDeg \\
\hline GILL2 1 & $\begin{array}{l}\text { Prom } \\
\text { Prol }\end{array}$ & $\begin{array}{l}\text { Prom } \\
\text { Prol }\end{array}$ \\
\hline FRAN & Prob & ProbEProDeg \\
\hline MARC & $\begin{array}{l}\text { Proc } \\
\text { Prov }\end{array}$ & $\begin{array}{l}\text { ProEProDeg } \\
\text { ProEProDeg }\end{array}$ \\
\hline SAWO & $\begin{array}{l}\text { Proc } \\
\text { Prov } \\
\text { Proz }\end{array}$ & $\begin{array}{l}\text { (Proc) EProdeg } \\
\text { (Prov) }^{\text {EProdeg }} \\
\text { (Prov) }^{\text {EProdeg }}\end{array}$ \\
\hline
\end{tabular}

\begin{tabular}{|c|c|}
\hline $\begin{array}{l}\text { Values of the co } \\
\text { KProdeg }\end{array}$ & $\begin{array}{l}\text { ints } \\
\text { EProdeg }\end{array}$ \\
\hline $0.143 \mathrm{~kg}$ Pro $/\left(\mathrm{kg}\right.$ Prob $\left.^{0.73 *} \mathrm{~d}\right)$ & 0.73 \\
\hline $0.042 / d$ & 1 \\
\hline $0.271 / d$ & 1 \\
\hline $0.09 \mathrm{~kg}$ Pro $/(\mathrm{kg}$ Prob * d) & 1 \\
\hline $0.023 \mathrm{M} \mathrm{AA} /\left(\mathrm{M} \mathrm{AA}^{0.87 * \mathrm{~d})}\right.$ & 0.87 \\
\hline $0.279 \mathrm{M} \mathrm{AA} /\left(\mathrm{M} \mathrm{AA}^{0.60 * \mathrm{~d})}\right.$ & 0.60 \\
\hline $0.04 \mathrm{M} \mathrm{AA} /(\mathrm{M} \mathrm{AA} * \mathrm{~d})$ & 1 \\
\hline $0.30 \mathrm{M} \mathrm{AA} /\left(\mathrm{M} \mathrm{AA}^{*} \mathrm{~d}\right)$ & 1 \\
\hline $0.10 \mathrm{M} \mathrm{AA}^{-}\left(\mathrm{M} \mathrm{AA}^{\star} \mathrm{d}\right)$ & 1 \\
\hline
\end{tabular}

1 Only 2 of the 10 compartments of the Gill2 model are considered.

Prob, Proc, Prol, Prom, Prov, and Proz $=$ Protein in empty body, in carcass, in liver, in muscle, in viscera, and in other tissues. $M=$ mole, $A A=$ amino acids.

The general expression of Prodeg is: Prodeg $=$ KProsyn ${ }^{*}$ independant variables ${ }^{\star} \mathrm{f}($ Nuti, AHor).

The OLTJ model accommodates with frame sizes that differ from the reference animal (DNAmax different) by assuming that, at similar degree of maturity:

- the rate of different functions in different steers (similar proportion of EBW) is proportional to mature weight at power 0.73 .

- growing ruminants have the same body composition.

Adipose tissues (AT) and triglycerides ( $\mathrm{Tg}$ ) compartments: lipid deposition

Adipose tissues are included in the different models as a major tissue for regulating homeostasis of energy in the body (Bauman and Currie, 1980). When an excess of energy above requirements for maintenance and protein accretion is supplied, it is stored as $\mathrm{Tg}$ in AT (no other forms of $\mathrm{Tg}$ storage are considered by any models, as $\mathrm{Tg}$ generally represents $95 \%$ of stored lipids in AT). Inversely, during periods of shortage of energy supply, $\mathrm{Tg}$ are mobilized in order to furnish energy for maintenance and synthetic processes other than those occurring in AT. The simplest way of simulating fat deposition (dAT) based on these concepts is accomplished in the OLTJ model by the equation:

$$
\begin{aligned}
& \mathrm{dAT}=(\mathrm{NE} \text { (intake) }-\mathrm{NE} \text { (maintenance) } \\
& \mathrm{NE}(\mathrm{dPro}) \text { ) } / 9.39
\end{aligned}
$$

where NE represents the net energy of intake, maintenance or proteosynthesis. This allows
dAT to be negative at low net energy intake. In these conditions, AT is mobilized to provide energy for maintenance and Pro deposition (by rank of priority), with a net energy value of 9.39 $\mathrm{Mcal} / \mathrm{kg}$ AT mobilized. This formulation reflects the priority of net energy utilization for maintenance, Pro deposition, and lipid deposition in descending rank of priority.

-Lipogenesis (Tgsyn)

In the other models, lipogenesis (TGsyn) and lipolysis (TGdeg) for $\mathrm{Tg}$ are defined more mechanistically (fig 8). Different expressions of TGsyn are used in these models, but the most general is developed in the GILL1 model:

$$
\begin{aligned}
& \text { Tgsyn }=\sum_{i=1}^{i=5} Y(i, T g) * K T g s y n(i) \star W E T g s y n(i) * \\
& f[N U T(i, j), \text { AHor }]
\end{aligned}
$$

where $\mathrm{i}=1$ for de novo Tgsyn from Acetyl-CoA or Ac,

$i=2$ for Tgsyn by reesteritication of preformed FA, $i=3$ for Tgsyn from Glu,

$i=4$ for Tgsyn from $\mathrm{Pr}$,

$i=5$ for Tgsyn from $A A$,

and where KTgsyn(i), and ETgsyn(i) are fixed constants (table III), $Y(i, T g)$ is the yield of $T G$ during the $\mathrm{i}$ transaction (based on stoichiometric reactions) and $f[N U T(i, j)$, AHor $]$ is defined as above. $W(t)$ is an estimator of the size of the compartment in which the transaction occurs. AHor(i) is the hormonal factor stimulating the $\mathrm{i}$ transaction: it is not explicitly included in the GILL1 model (which is 


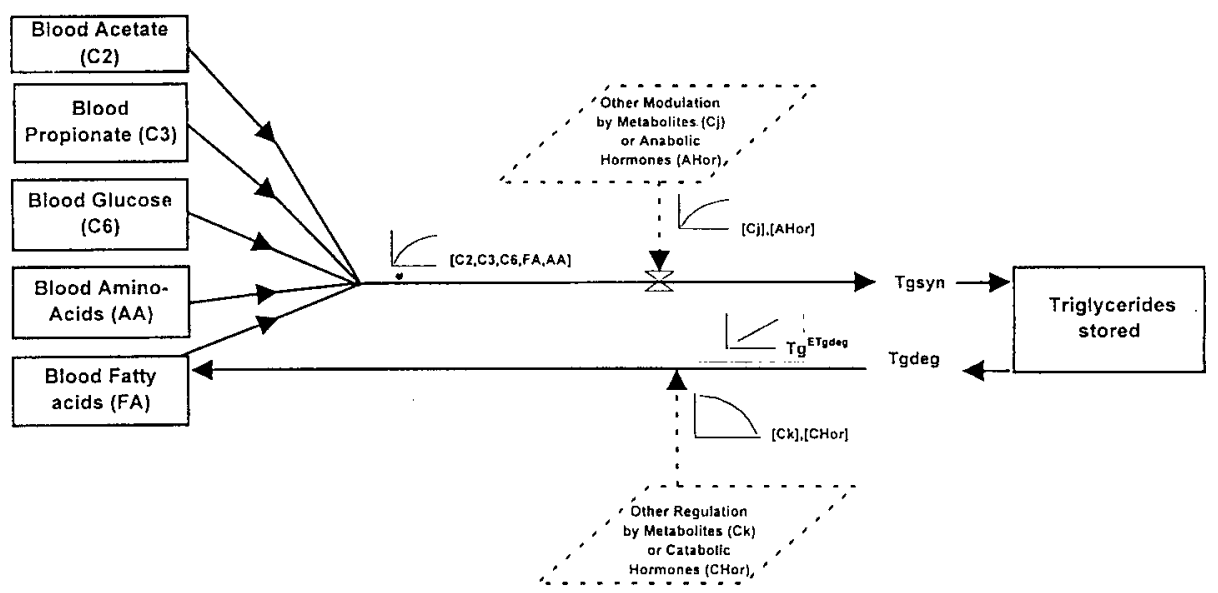

Figure 8. A general model of adipose tissue growth in growing animal.

simulated on $2 \mathrm{~d}$ ), but it was considered in (8) in order to give the most general expression of TGsyn, because other models include hormonal regulation (MARC and SAWO).

This general form of lipogenesis is developed in the GILL1 model, essentially because their objectives were more focused on the simulation of energy metabolism than for the other models. Consequently, they even included the possibility of AA to be lipogenic through Acetyl-CoA or pyruvate production (Reeds et al, 1982, Brodin and Yanovich, 1994). For the GILL1 model, all transactions defined above occur in two compartments of $\mathrm{Tg}$ : AT and liver, except for Tgsyn from $\mathrm{Pr}$ which is considered only in AT. In the MARC model, Tgsyn occurs only in AT, through Tgsyn de novo $(i=1)$, and via esterification of preformed FA $(i=2)$. The $W$ compartment is the weight of cytosol $W_{C}$ in AT (set at $4 \%$ of Pro in EBW) for de novo Tgsyn, and it is the product of $W_{c}$ and $T g(t)$ in $A T$ for the reesterification. For the SAWO model, de novo Tgsyn and esterification are related to Pro in the carcass and viscera $\left(\mathrm{W}(\mathrm{t})=\mathrm{Pro}_{\mathrm{c}}+\mathrm{Pro}_{\mathrm{v}}\right)$.

In the FRAN model, Tgsyn occurs through the form:

$$
\begin{aligned}
& \text { Tgsyn }=\text { KTgsyn * Tg }(t) *(1-(T g(t) / \\
& \text { TGmax } \left.(\mathrm{t})))^{\text {ETgsyn }} \text { * f[NUTi }\right]
\end{aligned}
$$

with values of KTgsyn and ETGsyn given in table III, and TGmax(t) calculated each day from the maximal lipid/ash ratio (TGmax $(\mathrm{t})=$ $15 \mathrm{~kg} \mathrm{Tg}(\mathrm{t}) / \mathrm{kg}$ ash(t), observed from slaugh- ter data). This later assumption is justified by the fact that AT develops after skeleton tissues (Brody, 1945): consequently, Tg at a given age is limited by the size of the skeleton, which illustrates empirically the priority of this tissue over the others.

\section{-Lipolysis (Tgdeg)}

In all models studied except OLTJ, Tgdeg is simulated by mass action using the general form:

$$
\begin{aligned}
& \text { Tgdeg }=K \text { Tgdeg } * W E T g d e g(t) * f[N U T i, \\
& \text { CHor }]
\end{aligned}
$$

where KTgdeg, ETgdeg are constants (table IV), CHor is an hormonal effect stimulating lipolysis (MARC and SAWO model), and NUT9 as previously defined (see also section "Regulation by the availability of nutrients"). $W(t)$ is the size of the pool in which lipolysis occurs (the same as those defined for lipogenesis). In all models, lipolysis occurs to provide $F A$ in the plasma for further utilization, and eventually glycerol for gluconeogenesis (GNG) in GILL1 and MARC models. In most of the models, the reesterification of fatty acid liberated from TG degradation in AT is not explicitly taken into account.

\section{Water (W) and ash (A) compartments}

Water and ash compartments are generally calculated empirically from the Pro compartment or from allometric relationships. For example, in OLTJ and MARC models, ash 
and water in EBW are given by:

$\mathrm{A}+\mathrm{W}+$ Pro $=$ fat free empty body mass $=$ (Pro / 0.2201)

Only the FRAN model is partially mechanistic for the A compartment. Mineral availability is not limiting, and only ash synthesis in the skeleton is considered without mineral mobilization from this pool (irreversible skeletal growth):

$$
\begin{aligned}
& \text { Asyn }=K A s y n * A(t) *(1-(A(t) \\
& / A \max (t)))^{E A s y n} * f[N U T i]
\end{aligned}
$$

with $\operatorname{Amax}(t)=0.3 * \operatorname{Pro}(t)$. As close relationships exist between $A$ and Pro deposition, this later point is used to take into account the energy requirement for $\mathrm{A}$ deposition (ill-known) by relating it to energy needs for Pro deposition. As proportions of $\mathrm{W}, \mathrm{A}$, and Pro in empty body are relatively constant, $W=$ is set to $2.38 *(A+$ Pro $)$, based on serial slaughter experiments.

\section{Biochemical compartments}

This part of the discussion will not cover all compartments involved in the different models. It will be focused on Glu metabolism (for energetic reasons), AA pool (because of the interrelationships between Glu, and Pro and oxidatives processes), and ATP pools. Some intermediary components (NADPH, glycerol, lactate) will be only mentioned if necessary OLTJ model is not considered (no biochemical compartments).

Table III. Main values of constants of lipogenic transactions (Tgsyn) for the different lipid ( $\mathrm{Tg}$ )

\begin{tabular}{|c|c|c|c|c|c|c|}
\hline \multirow[t]{2}{*}{ Model } & \multirow{2}{*}{$\begin{array}{l}\text { Nutrient } \\
\text { required }\end{array}$} & \multirow[t]{2}{*}{ Compartment } & \multirow[t]{2}{*}{ Independant variables } & \multicolumn{3}{|c|}{ Values of the constants } \\
\hline & & & & KTgsyn ${ }^{1}$ & YTg ${ }^{2}$ & ETgsyn \\
\hline FRAN & - & AT & $W(T A)^{\star}(1-W(T A) / W T A m a x)^{E T g s y n}$ & 3 & 4 & 10 \\
\hline \multirow[t]{2}{*}{ MARC } & Acetate & Cytosol in AT & $W(\text { Cyt })^{\text {ETgsyn }}$ & 0.367 & $1 / 24$ & 1.375 \\
\hline & Fatty acids & Cytosol in AT & $W(\text { Cyt })^{\text {ETgsyn }}$ & 0.003 & $1 / 3$ & 1.030 \\
\hline \multirow[t]{5}{*}{ GILL } & Acetyl-CoA & Liver + AT & $W(L+A T) E T g s y n$ & 1.26 & $1 / 24$ & 1 \\
\hline & Fatty acids & Liver + AT & $W(L+A T)^{E T g s y n}$ & 0.141 & $1 / 3$ & 1 \\
\hline & Glucose & Liver + AT & $W(L+A T)$ ETgsyn & 0.653 & 0.007 & 1 \\
\hline & Amino-acids & Liver + AT & $W(L+A T)^{E T g s y n}$ & 0.864 & 0.054 & 1 \\
\hline & Propionate & AT & W(AT) ETgsyn & 0.468 & $1 / 27$ & 1 \\
\hline \multirow[t]{2}{*}{ SAWO } & Acetate & Proc + Prov & $W(\text { Proc + Prov) })^{\text {ETgsyn }}$ & 0.346 & $1 / 24$ & 0.878 \\
\hline & Fatty acids & Proc + Prov & $W(\text { Proc + Prov) })^{E T g s y n}$ & 0.00518 & 1 & 0.902 \\
\hline
\end{tabular}
compartments involved in different mechanistic models of growing ruminant 4

$1 \mathrm{M}$ Nut / ( $\mathrm{kg}$ (Compartment)Etgsyn * $\mathrm{d}$ ); $2 \mathrm{~kg} \mathrm{M} \mathrm{Tg} / \mathrm{kg} \mathrm{M} \mathrm{Nut;}{ }^{3} \mathrm{KTgsyn}=0.139 \mathrm{~kg}$ lipid / ( $\mathrm{kg}$ lipids * $\mathrm{d}$ ) in the FRAN model; ${ }^{4} \mathrm{~W}=$ weight of the compartment, $\mathrm{AT}=$ adipose tissue, $\mathrm{Cyt}=$ cytosol in adipose tissue, $\mathrm{L}=$ liver, Proc and Prov $=$ Protein in the carcass and viscera, $M=$ mole, Nut $=$ nutrient.

General expression of lipogenesis is $\mathrm{Tgsyn}=\mathrm{YTg}^{*} \mathrm{Ktgsyn}{ }^{*} \mathrm{f}$ (independant variables) ${ }^{*} \mathrm{f}(\mathrm{Nut}, \mathrm{AHor})$, see text (equation 7).

Table IV. Main values of constants of lipolytic transactions (Tgdeg) for the different lipid (Tg) compartments involved in different mechanistic models of growing ruminant 1.

\begin{tabular}{|c|c|c|c|c|}
\hline & & & KTgdeg & Igdeg \\
\hline FRAN & Adipose tissues & $W(T A)^{E T g D e g}$ & $0.05 \mathrm{~kg} \mathrm{Tg} /(\mathrm{kg} \mathrm{Tg} * \mathrm{~d})$ & 1 \\
\hline MARC & Adipose tissues & $W($ Cyt $) \star W(T A)^{E T g D e g}$ & $\mathrm{Nl}$ & $\mathrm{NI}$ \\
\hline GILL & Adipose tissues & $W(T A)^{E T g D e g}$ & $0.243 \mathrm{e}-3 \mathrm{M} \mathrm{Tg} /(\mathrm{kg} \mathrm{Tg} * \mathrm{~d})$ & 1 \\
\hline SAWO & Adipose tissues & (Prov + Proc) $)^{\text {TgDeg }}$ & 5.46 e-3 M Tg $/\left(\mathrm{kg}(\text { Proc }+ \text { Prov })^{0.75} \star \mathrm{d}\right)$ & 0.75 \\
\hline
\end{tabular}

Model Compartment Independant variables Values of the constants

$1 \mathrm{~W}=$ weight of the compartment, $\mathrm{AT}=$ adipose tissue; $\mathrm{Cyt}=$ cytosol in adipose tissue; Proc and Prov $=$ Protein in the carcass and viscera; $\mathrm{M}=$ mole. $\mathrm{Tg}=$ tryglycerides. $\mathrm{NI}=$ not indicated in the publication.

The general expression of lipolysis is Tgdeg $=$ Ktgdeg ${ }^{*} \mathrm{f}$ (independant variables) ${ }^{*} \mathrm{f}$ (Nut, CHorm). 
The Glu pool

The common inputs in Glu pool consist of absorption of Glu, gluconeogenesis from $\mathrm{Pr}$, $A A$, and glycerol. Model-specific inputs are also considered: GNG from lactate (MARC and SAWO models), and glycogen mobilization (GILL1 model). Yield of Glu through glycerol, lactate, and glycogen are based on stoichiometric coefficients. The fraction of $\mathrm{Pr}$ converted to Glu is set to 0.3 (GILL1, SAWO), 0.6 (FRAN), 0.7 (MARC), with a yield of $0.5 \mathrm{M}$ Glu / $\mathrm{MPr}$, the remainder of $\mathrm{Pr}$ is oxidized totally for energy production.

The AA pool- connection with Glu pool

Amino acids are removed from the AA pool, for Pro synthesis with a requirement of 5 moles ATP/mole of peptide bond synthesised (GILL1, MARC and SAWO), or 4 moles ATP (+1 ATP for transport, GILL2), or its equivalent in term of Acetyl-CoA units (FRAN model). The requirement for ATP connects Pro synthesis and body growth with energetic metabolism. In the GILL2 model, a specific intracellular AA pool is defined for each Pro compartment considered. The validity of an single (uniform) pool from which AA are used, is not in the scope of this paper. However, Baldwin et al (1994) suggest that distinct AA pools have to be considered (AA channelling), because AA oxidation probably occurs in a different pool from the one from which Prosyn takes place.

The outputs of $A A$ pools are also related to their contribution to GNG (with production of $C_{2}$ units), and oxidation. Whereas the proportion of AA entering Prosyn or catabolic pathways is examined below (see section "Regulation by the availability of nutrients"), the partition of $A A$ between oxidative and gluconeogenic pathways is fixed in the FRAN and GILL1 model with a ratio of $5: 1$ between oxidation and GNG (Lindsay, 1976). Yield of Glu from AA is 0.32 (FRAN), 0.36 (GILL1 and SAWO), and 0.47 (MARC) M Glu/M AA. In GILL1, MARC and FRAN model, this reaction provides 0.5 to $0.6 \mathrm{M}$ urea / M AA. No relationship between AA in liver and Glu is included in the GIIL2 model, but oxidation of AA directly occurs in the blood AA pool (mass action law). Inputs in AA blood pool are AA absorbed from digestive tract (see section "Nutritional inputs") and body Pro turnover (cf above).

The oxidative metabolism: ATP, Acetyl-CoA pools (fig 9)

In the FRAN model, maintenance energy requirements (cf below) are first met by the energy produced during conversion of absorbed nutrients and from catabolic process (glycolysis, GNG, and lipolysis), and secondly by oxidation of $C_{2}$ units (on a basis of $0.928 \mathrm{MJ}$ (12 M ATP) / M Acetyl-CoA oxidized). To account for further increases in maintenance requirement with increased metabolizable energy intake, a supplementary energy transaction consuming energy (substrate cycling) is introduced, increasing rapidly when $\mathrm{C}_{2}$ concentration is high.

In the more detailed model of GILL1, energy transactions are considered in terms of ATP (yields of ATP from stoichiometric reactions). Inputs to the ATP pool come from oxidative processes $\left(\mathrm{CO}_{2}\right.$ production from $\mathrm{AA}$, Acetyl-CoA, FA, Glu and $\mathrm{C}_{3}$ oxidation), from lipogenesis (from $A A$ and Glu), and GNG (from AA). ATP outputs arise from ATP requirements for biosynthetic processes (Tgsyn from different precursors (see section "Adipose tissues and triglycerides compartments"), Prosyn, glycogen storage, GNG from $\mathrm{C}_{3}$ ), for catabolic processes (NADPH production from glucose, conversion of $\mathrm{AC}$ and $\mathrm{Bu}$ to AcetylCoA), for nitrogen excretion in urea, and for maintenance (defined empirically, cf below). To prevent excess accumulation in the ATP pool, it was necessary to introduce a supplementary ATP degradation representing some futile cycles and other non defined ATP degradations. In the GILL2 model, the energy cost associated with protein turnover and $\mathrm{Na}^{+}-\mathrm{K}^{+}$ ion transport is considered in term of ATP transaction.

In SAWO and MARC models, undefined energy expenditures (UND, expressed in terms of ATP/d) included processes of ion or nutrient transport, respiration, and circulation. In the MARC model, UND is partitioned between ATP expenditure which are solely dependent on EBW, and those related to nutrient availability, whereas in the SAWO model UND is a function of size of the Pro mass in the different compartments. In these models, the ATP pool is kept in balance between the use of ATP (UND, biosynthetic processes, cost of physiological work and nutrients absorption, turn-over), and the production of ATP by oxidation of absorbed nutrients, Glu conversion to lactate, and Glycerol to Glu, to which are added production of ATP originating from FA, acetate and Glu oxidation. 

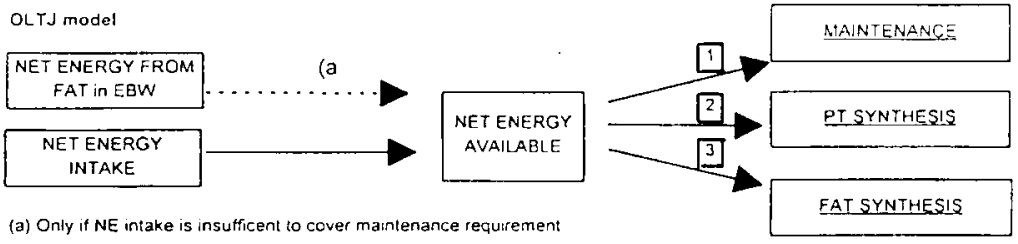

(a) Only if NE intake is insutficent to cover mantenance requirement
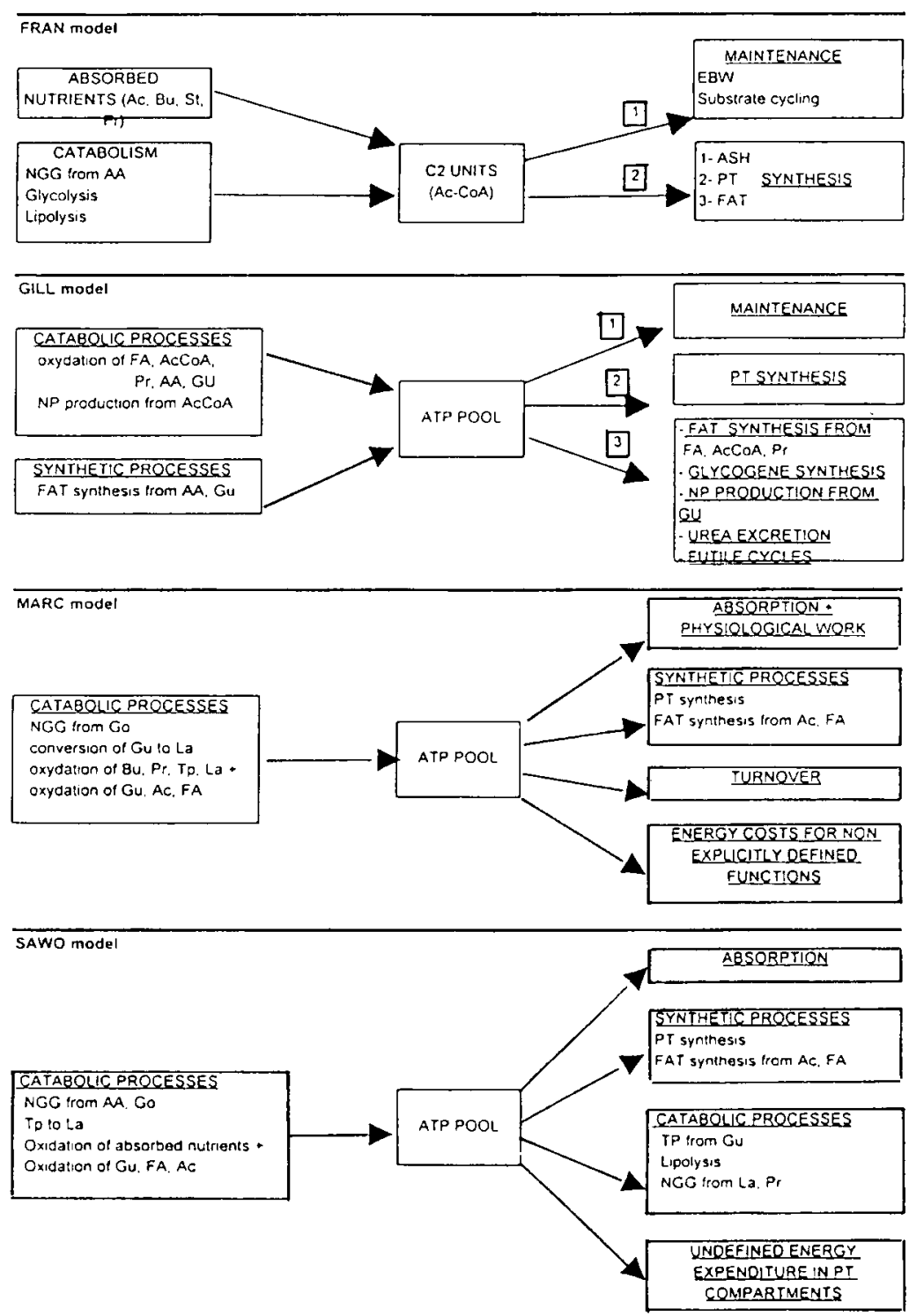

Figure 9. Different concepts of regulation of biological processes by energy availability in mechanistic models of growing ruminant. 
Maintenance (Maint)

Maintenance requirement is a term referring to the flux of energy (or nitrogen) in the feed unit systems used to sustain animal life. Consequently, it represents a very high level of aggregation, and is generally defined empirically (OLTJ and FRAN models) by:

$$
\text { Maint }=A * E B^{B}
$$

with $A=0.0841,0.129$, and $B=0.75,0.67$, respectively. In GILL1 model, Maint is also defined empirically from metabolic full body weight, the rate of body gain, and from digestible energy. In these 3 models, energy for Maint is provided at the expense of the "energetic pool», i.e. NE intake (OLTJ), $C_{2}$ pool (acetyl-Coa units, FRAN), or ATP pools (GILL1). Meeting the energy requirement for Maint is given the first priority, then remaining energy is used for other purposes (eventually ash, then Pro and Tg synthesis). In the SAWO and MARC model, the Maint requirements are defined more mechanistically, and expressed in term of ATP transactions.

\section{Fluxes and their regulations}

\section{Nutritional inputs}

Nutrient inputs for the growth and metabolism are defined by fluxes of continuously absorbed nutrients. These fluxes are:

- either related to intake of a reference diet by $\mathrm{F} *$ BW 0.75 , with $\mathrm{F}=95 \mathrm{~g} / \mathrm{kg}$ BW0.75 in MARC model connected with the digestive sub-model of Baldwin et al, (1987), or $F$ represents the level of feed intake in multiple of maintenance (SAWO).

- or arbitrarily set to a value for a given diet (FRAN, GILL1 and GILL2 models).

From this, it results that ruminants simulated by FRAN and GILL1 and GILL2 models can not loose weight, as clearly, this objective is not included in these models. The MARC and SAWO models allow a decrease of BW, when $F$ is either below the reference value $(95 \mathrm{~g} / \mathrm{kg}$ $\mathrm{EB}^{0.75}$ ), or below maintenance value, and indeed they simulate negative energy retention in underfed animals (see section «Internal and external validation").

\section{Regulation by the availability of nutrients}

The influence of availability of nutrients on growth and body composition in the OLTJ model is taken into account at a very high level of aggregation through 2 factors NUT(DNA), and NUT(Prosyn), altering DNAsyn and Prosyn respectively. They are defined by:

$$
\begin{aligned}
& \text { NUT(DNA) }=a+b{ }^{*} P \\
& \text { and NUT(Prosyn) }=c+d * P /(e+P)
\end{aligned}
$$

where $P$ is a proportion (between 0.2 and 1.4) of normal metabolizable energy intake defined for a given empty body weight of the reference steer. The negative value of a $(-0.7)$ and the value of $b(1.7)$ causes DNA and Pro to decrease when $P$ is below 0.41 (i.e. actual metabolizable energy intake below $41 \%$ of normal intake), and consequently it results in a loss of weight (see section "Internal and external validation").

Most of the coefficients NUTi used in the catabolic and anabolic transactions in the models are less aggregated than the nutritional processes in the OLTJ model. In these models, transactions in equations 1 to 10 can be simplified by:

$$
\begin{aligned}
& \text { rate of transaction }=V_{\max }{ }^{*} \mathrm{f}[\mathrm{NUTi}, \mathrm{AHor} \\
& \text { or } \mathrm{CHor}]
\end{aligned}
$$

with

$$
\mathrm{f}[\mathrm{NUTi}]=\left(\mathbf{1}+\Sigma(\mathrm{Ki} / \mathrm{C}[\mathrm{NUTT}])^{\alpha}\right)^{-1}
$$

where $\mathrm{Ki}$ is the Michaelis-Menten affinity constant for the substrate NUTi at the concentration C[NUTi], with $\alpha \leq-1$ for inhibition, and $\alpha \geq 1$ for stimulation. Ki or Vmax may be affected by $\mathrm{CH}$ or or AHor (see section "Partition of fluxes: the hormonal regulation"). Higher values of $\alpha$ are considered when points of inflexion are needed (sigmoidal reactions with steeper sigmoidicity when $\alpha$ increases). For $\alpha<0$, at low concentration of $\mathrm{Ci}$ the reaction proceeds at low rate, whereas at normal or high concentration of $\mathrm{Ci}$, the reaction proceeds at high rate (cf below). Table $V$ summarizes the regulating nutrients and the sigmoidicity of equation f[CNUTi].

All reactions are regulated by at least one factor, generally the principal substrate of the reaction. For example, Tgsyn from Ac, or from FA, Pro synthesis, and Glu production are regulated by concentrations of $A c$, or FA, AA and $\mathrm{Pr}$, respectively. In many transactions, auxiliary substrates play a permissive role: e.g. in MARC and SAWO models, lipogenesis from FA depends also on Glu availability to furnish glycerol backbone for $\mathrm{Tg}$ synthesis. Up to 4 substrates have been included in some transactions, e.g. Tgsyn from $\mathrm{Pr}$ in AT in the GILL1 model necessitates a low level of 
Table V. Substrat modulation of the main transactions occuring in the models of growing ruminant.

\begin{tabular}{|c|c|c|c|c|c|}
\hline \multirow[t]{2}{*}{ Model } & \multirow[t]{2}{*}{ Reactions considered } & \multicolumn{2}{|c|}{$\begin{array}{c}\text { Stimulating } \\
\text { substrates (i) }\end{array}$} & \multirow[t]{2}{*}{$\begin{array}{l}\text { Inhibiting } \\
\text { substrates (j) }\end{array}$} & \multirow[t]{2}{*}{$\begin{array}{l}\text { Sigmoidicity } \\
\text { of the equation }\end{array}$} \\
\hline & & Principal & Auxiliary & & \\
\hline FRAN & Lipogenesis from $\mathrm{Cz}$ & $\mathrm{Cz}$ & Glu & & $\alpha(i)=1$ \\
\hline GILL1 & Lipogenesis from $\mathrm{Cz}$ & $\mathrm{Cz}$ & ATP, Glu, Np & & $\alpha(i)=1$ \\
\hline MARC & Lipogenesis from Ac & $A C$ & Glu & & $\alpha(i)=1$ \\
\hline SAWO & Lipogenesis from Ac & $\mathrm{Ac}$ & Glu & Ts & $\alpha(\mathbf{i})=1, \alpha(\mathbf{j})=-1$ \\
\hline GILL1 & Lipogenesis from AA & AA & Glu, $N p$ & & $\alpha(i)=1$ \\
\hline GILL1 & Lipogenesis from FA & FA & ATP, Glu & & $\alpha(i)=1$ \\
\hline MARC, SAWO & Lipogenesis from FA & FA & Glu & & $\alpha(i)=1$ \\
\hline GILL1 & Lipogenesis from Glu & Glu & $\mathrm{Np}$ & & $\alpha(\mathrm{Glu})=2, \alpha(\mathrm{Np})=1$ \\
\hline GILL1 & Lipogenesis from $\mathrm{Pr}$ & $\mathrm{Pr}$ & ATP, Glu, Np & & $\alpha(i)=1$ \\
\hline GILL1 & Lipolysis & TG & & ATP & $\alpha(\mathrm{TG})=20, \alpha(\mathrm{ATP})=-4$ \\
\hline MARC & Lipolysis & & & FA & $\alpha(j)=-1$ \\
\hline SAWO & Lipolysis & $\mathrm{TG}$ & & & $\alpha(i)=5$ \\
\hline $\begin{array}{l}\text { FRAN } \\
\text { MARC, SAWO, } \\
\text { and GILL2 }\end{array}$ & $\begin{array}{l}\text { Pro synthesis from } A A \\
\text { Pro synthesis from } A A\end{array}$ & $\begin{array}{l}\mathrm{AA} \\
\mathrm{AA}\end{array}$ & $\mathrm{Cz}$ & & $\begin{array}{l}\alpha(i)=1 \\
\alpha(i)=1\end{array}$ \\
\hline FRAN, MARC & Glu production from AA & $A A$ & & & $\alpha(i)=1$ \\
\hline GILL1 & Glu production from AA & AA & & Glu & $\alpha(i)=1, \alpha(j)=-1$ \\
\hline GILL1 & Glu production from Gy & Gy & & Glu & $\alpha(G y)=4, \alpha(G \mid u)=-20$ \\
\hline GILL1 & Glu production from $\mathrm{Pr}$ & $\mathrm{Pr}$ & ATP & Glu & $\alpha(i)=1, \alpha(j)=-1$ \\
\hline MARC, SAWO & Tp production from Glu & Glu & & & $\alpha(i)=1$ \\
\hline MARC & La production from Glu & Glu & & & $\alpha(i)=1$ \\
\hline FRAN & $\mathrm{Cz}$ production from Glu & Glu & & & $\alpha(G \mid u)=5$ \\
\hline GILL1 & $\mathrm{Cz}$ Production from $\mathrm{Ac}$ & $\mathrm{Ac}$ & ATP & & $\alpha(i)=1$ \\
\hline FRAN & $\begin{array}{l}\mathrm{Cz} \text { utilisation during } \\
\text { substrate cycling }\end{array}$ & $\mathrm{Cz}$ & & & $\alpha(\mathrm{Cz})=5$ \\
\hline GILL1 & $\mathrm{CO}_{2}$ production from $\mathrm{Cz}$ & $\mathrm{Cz}$ & & ATP & $\alpha(\mathrm{i})=1, \alpha(\mathrm{j})=-1$ \\
\hline MARC, SAWO & $\mathrm{CO}_{2}$ production from $\mathrm{Ac}$ & $A c$ & & & $\alpha(i)=1$ \\
\hline GILL1 & $\mathrm{CO}_{2}$ production from Gilu & Glu & & ATP & $\alpha(i)=1, \alpha(j)=-1$ \\
\hline MARC, SAWO & $\mathrm{CO}_{2}$ production from Glu & Glu & & & $\alpha(i)=1$ \\
\hline GILL1 & $\mathrm{CO}_{2}$ production from $\mathrm{Pr}$ & $\operatorname{Pr}$ & & ATP & $\alpha(i)=1, \alpha(j)=-1$ \\
\hline GILL1 & $\mathrm{CO}_{2}$ production from $\mathrm{FA}$ & FA & & ATP & $\alpha(i)=1, \alpha(j)=-1$ \\
\hline MARC, SAWO & $\mathrm{CO}_{2}$ production from $\mathrm{FA}$ & $\mathrm{FA}$ & & & $\alpha(i)=1$ \\
\hline GILL1 & $\mathrm{CO}_{2}$ production from $\mathrm{AA}$ & AA & & ATP & $\alpha(i)=1, \alpha(j)=-1$ \\
\hline GILL1 & Gy production from Glu & Glu & ATP & Gy & $\alpha(i)=1, \alpha(j)=-1$ \\
\hline GILL1 & $\mathrm{Np}$ production from $\mathrm{Cz}$ & $\mathrm{Cz}$ & & Np, ATP & $\alpha(i)=1, \alpha(j)=-1$ \\
\hline GILL1 & Np production from Glu & Glu & ATP & $\mathrm{Np}$ & $\alpha(i)=1, \alpha(j)=-1$ \\
\hline
\end{tabular}

$\mathrm{AA}=$ Amino acids (considered as Nitrogen), $\mathrm{AC}=$ acetate, $\mathrm{Cz}=$ Acetyl-CoA, FA = Fatty acids; Go = glycerol; $\mathrm{Glu}=$ Glucose; $\mathrm{Gy}=$ Glycogen; $\mathrm{La}=$ lactic acid; $\mathrm{Np}=\mathrm{NADPH}, \mathrm{Pr}=$ Propionate; $\mathrm{TG}=$ triglycerides in adipose tissues; $T s=$ circulating triglycerides; $T p=$ triose phosphate.

Rate of reactions are defined by $V \max * f[N U T i]$ with $f[N U T i]=\left(1+\Sigma(\mathrm{Ki} / \mathrm{C}[\mathrm{NUTi}])^{\alpha(i))^{-1}}\right.$ 
Table VI. Influence of values of affinity constants $K$ of the substrates on the velocity of the main transactions described in the models of growing ruminant.

\begin{tabular}{|c|c|c|c|c|c|}
\hline & & \multirow{2}{*}{\multicolumn{2}{|c|}{ Substrates }} & \multirow{3}{*}{\multicolumn{2}{|c|}{$\begin{array}{l}\mathrm{K} \text { (value relative to reference (ref) or } \\
\text { initial (0) concentration of substrate) }\end{array}$}} \\
\hline \multirow[t]{2}{*}{ Model } & \multirow[t]{2}{*}{ Reactions considered } & & & & \\
\hline & & Stimulating & Inhibiting & & \\
\hline FRAN & Ash synthesis & $\mathrm{Cz}$ & & $0.25 \mathrm{Cz}_{\mathrm{ref}}$ & \\
\hline FRAN & Lipogenesis from $\mathrm{Cz}$ & $\mathrm{Cz}, \mathrm{Glu}$ & & $0.50^{*} \mathrm{Cz}_{\mathrm{ref}}, 0.50^{*} \mathrm{Glu}$ ref & \\
\hline GILL1 & Lipogenesis from $\mathrm{Cz}$ & $\mathrm{Cz}, \mathrm{ATP}, \mathrm{Glu}, \mathrm{Np}$ & & $0.10^{*} \mathrm{Cz}_{0}, 0.10^{*} \mathrm{ATP}, 0.10^{*} \mathrm{Glu}_{0}, 1^{*} \mathrm{~Np}$ & \\
\hline MARC & Lipogenesis from Ac & Ac, Glu & & $0.50^{*} \mathrm{Ac}_{\mathrm{re}}, 0.50^{\star} \mathrm{Glu} \mathrm{u}_{\mathrm{ret}}$ & $(+)$ \\
\hline SAWO & Lipogenesis from Ac & Ac, Glu & Ts & $1^{*} \mathrm{Ac}_{\text {ref }}, 1^{*} \mathrm{Glu}$ ref, $1.5^{\star} \mathrm{Ts}_{\text {ref }}$ & $(+)$ \\
\hline GILL1 & Lipogenesis from FA & FA, ATP, Glu & & $0.16^{*} \mathrm{FA}_{0}, 0.10^{*}$ ATP, $0.10^{*} \mathrm{Glu}_{0}$ & \\
\hline MARC & Lipogenesis from FA & FA, Glu & & $0.50^{*} \mathrm{FA}_{\text {ref }}, 0.50^{*} \mathrm{Glu}_{\text {ref }}$ & $(+)$ \\
\hline SAWO & Lipogenesis from $\mathrm{FA}$ & FA, Glu & & $1{ }^{*} \mathrm{FA}$ ref, $1^{*} \mathrm{G} l \mathrm{u}_{\mathrm{ref}}$ & \\
\hline GILL1 & Lipogenesis from Glu & Glu, Np & & $2^{*} \mathrm{Glu}_{0}, 1^{*} \mathrm{~Np} \mathrm{p}_{0}$ & \\
\hline GILL1 & Lipogenesis from $\mathrm{Pr}$ & Pr, ATP, Glu, Np & & $123^{*} \mathrm{Pr}_{0}, 0.10^{*} \mathrm{ATP}, 0.10^{*} \mathrm{G} \mathrm{u}_{0}, 1^{*} \mathrm{~Np}_{0}$ & \\
\hline GILL1 & Lipogenesis from $A A$ & AA, Glu, Np & & $650^{*} \mathrm{AA}_{0}, 0.10^{*} \mathrm{Glu}_{0}, 1^{\star} \mathrm{Np}_{0}$ & \\
\hline MARC & Lipolysis & & FA & $0.33^{*} \mathrm{FA}_{\text {ref }}$ & $(-)$ \\
\hline SAWO & Lipolysis & $T G$ & & $1^{*} T_{g_{\text {ref }}}$ & $(-)$ \\
\hline FRAN & Pro synthesis from AA & $\mathrm{AA}, \mathrm{Cz}$ & & $0.50^{\star} \mathrm{AA}_{\text {ret }}, 0.33^{\star} \mathrm{C} \mathrm{z}_{\text {ref }}$ & \\
\hline MARC & Pro synthesis from AA & AA & & $1 * \mathrm{AA}_{\mathrm{ref}}$ & \\
\hline SAWO & Pro synthesis from AA & AA & & $0.20^{*} A A_{\text {ret }}$ & $(+)$ \\
\hline GILL2 & Pro synthesis from AA & AA & & $0.10^{*} A A_{\text {ref }}$ & \\
\hline FRAN & Glu production from $\mathrm{AA}$ & AA & & $2^{*} \mathrm{AA}_{\text {ref }}$ & \\
\hline MARC & Glu production from AA & AA & & $1^{\star} \mathrm{AA}$ ref & $(-)$ \\
\hline GILL1 & Glu production from AA & AA & Glu & $7^{\star} \mathrm{AA}_{0}, 0.50^{\star} \mathrm{Glu}_{0}$ & \\
\hline GILL1 & Glu production from Gy & Gy & Glu & $0.1^{\star} \mathrm{Gy}_{0}, 0.50^{\star} \mathrm{Glu}_{0}$ & \\
\hline GILL1 & Glu production from $\mathrm{Pr}$ & Pr, ATP & Glu & $1.85^{*} \operatorname{Pr}_{0}, 0.10^{\star}$ ATP, $2^{\star} \mathrm{Glu}_{0}$ & \\
\hline MARC & Tp production from Glu & Glu & & $1^{*} \mathrm{Glu}_{\mathrm{ref}}$ & \\
\hline SAWO & Tp production from Glu & Glu & & $t^{*} \mathrm{Glu}_{\mathrm{ref}}$ & $(+)$ \\
\hline MARC & La production from Glu & Glu & & $0.50^{*} \mathrm{Glu}$ ref & \\
\hline FRAN & $\mathrm{Cz}$ production from Glu & Glu & & $1.5^{\star} \mathrm{Glu}_{\mathrm{ref}}$ & \\
\hline GILL1 & $\mathrm{Cz}$ Production from $\mathrm{AC}$ & AC, ATP & & $1.77^{*} \mathrm{Ac}_{0}, 0.10^{*} \mathrm{ATP}$ & \\
\hline FRAN & $\begin{array}{l}\text { Cz utilisation during } \\
\text { substrate cycling }\end{array}$ & $\mathrm{Cz}$ & & $4^{\star} \mathrm{C} z_{\text {ref }}$ & \\
\hline GILL1 & $\mathrm{CO}_{2}$ production from $\mathrm{Cz}$ & $\mathrm{Cz}$ & ATP & $2.74^{*} \mathrm{C} z_{0}$ & \\
\hline MARC & $\mathrm{CO}_{2}$ production from $\mathrm{AC}$ & Ac & & $2^{\star} A c_{\text {ref }}$ & \\
\hline SAWO & $\mathrm{CO}_{2}$ production from $\mathrm{AC}$ & $A C$ & & $1^{*} \mathrm{AC}_{\mathrm{ret}}$ & \\
\hline GILL1 & $\mathrm{CO}_{2}$ production from Glu & Glu & ATP & $30^{*} \mathrm{Glu}$ & \\
\hline MARC & $\mathrm{CO}_{2}$ production from Glu & Glu & & $6^{*} \mathrm{Glu}_{\mathrm{ref}}$ & $(+)$ \\
\hline SAWO & $\mathrm{CO}_{2}$ production from Glu & Glu & & $5^{*} \mathrm{Glu}_{\mathrm{ref}}$ & $(+)$ \\
\hline GILL1 & $\mathrm{CO}_{2}$ production from $\mathrm{Pr}$ & $\operatorname{Pr}$ & ATP & $2.5^{*} \mathrm{Pr}_{0}$ & \\
\hline GILL1 & $\mathrm{CO}_{2}$ production from $\mathrm{FA}$ & FA & ATP & $25.7^{\star} F A_{0}$ & \\
\hline MARC & $\mathrm{CO}_{2}$ production from $\mathrm{FA}$ & FA & & $7^{\star} \mathrm{FA}$ ret & \\
\hline SAWO & $\mathrm{CO}_{2}$ production from $\mathrm{FA}$ & FA & & $3^{*} \mathrm{FA}_{\mathrm{ret}}$ & \\
\hline GILL1 & $\mathrm{CO}_{2}$ production from $\mathrm{AA}$ & AA & ATP & $5.7^{*} \mathrm{AA}_{0}$ & \\
\hline GILL1 & Gy production from Glu & Glu, ATP & Gy & $2.8^{\star} \mathrm{Glu}_{0}$ & \\
\hline GILL1 & $\mathrm{Np}$ production from $\mathrm{Cz}$ & $\mathrm{Cz}$ & $\mathrm{Np}, \mathrm{ATP}$ & $0.73^{\star} \mathrm{Cz}_{0}, 1^{\star} \mathrm{Np}_{0}$ & \\
\hline GILL1 & Np production from Glu & Glu, ATP & $\mathrm{Np}$ & $0.64^{*} \mathrm{Glu} u_{0}, 1^{*} \mathrm{~Np}_{0}$ & \\
\hline
\end{tabular}

$\mathrm{AA}=$ Amino acids, $\mathrm{Ac}=$ acetate, $\mathrm{Cz}=$ Acetyl-Coa, $\mathrm{FA}=$ Fatty acids; $\mathrm{Glu}=$ Glucose; $\mathrm{Gy}=$ Glycogen; $\mathrm{La}=$ lactic acid; $\mathrm{Np}=\mathrm{NADPH}, \mathrm{Pr}=$ Propionate; $\mathrm{TG}=$ triglycerides in adipose tissues; $\mathrm{Ts}=$ circulating triglycerides; $T p=$ triose phosphate. $(+)$ and $(-)$ : indicate a hormonal regulation $((+)=$ Anabolic hormone, (-) = catabolic hormone).

Rate of reactions are defined by $V \max { }^{*} \mathrm{f}[\mathrm{NUTi}]$ with $\mathrm{f}[\mathrm{NUTi}]=(1+\Sigma(\mathrm{Ki} / \mathrm{C}[\mathrm{NUTi}]) \alpha(\mathrm{i}))^{-1}$ 
aggregation, and a very precise description of mechanisms regulating the process. Simultaneously, some transactions may be inhibited by only one compound, which is generally the end-product of the reaction (e.g.; GNG from AA inhibited by Glu concentration in FRAN and MARC models), or a coproduct of the reaction (e.g. NADPH production from Acetyl-CoA is inhibited by NADPH concentration and ATP in GILL1 model).

In some models, the relative values of affinity constants (expressed as a proportion of the reference (or initial) concentration of the substrate, table VI) of a substrate in several competing transactions allow to give its priority of utilization for a particular transaction. In the GILL1 model, the relative $\mathrm{Ki}$ for ash, protein and lipids synthesis are respectively $0.25,0.33$, and 0.50 times Acetyl-CoA normal concentration, indicating that in case of lack of energy (Iow Acety-Coa concentration), lipogenesis will first be limited, then protein synthesis, and finally skeleton synthesis. In the same way, this theoretical formulation accounts for interactions among nutrient utilization. In all models (except OLTJ model), GNG can occur with AA as precursor of glucose. However, this reaction will occur at an appreciable rate only when $A A$ concentration reach between 2, and 7 times the $A A$ reference concentration. Moreover, when comparing $K$ value of $A A$ for GNG and Prosyn in FRAN model, the priority is given for Prosyn ( $K=$ $2 *$ AAref for $G N G$ and $K=0.5 * A A r e f)$. Furthermore, in the GILL1 model, the fact that Glu concentration inhibits $G N G$ reflects the inhibition of hepatic GNG from $A A$, when availability in others precursors $(\mathrm{Pr})$ is high. Simultaneously, the sigmoidicity of reaction (table $\mathrm{V}$ ) aliows the reaction to be maximal (or minimal) as long as the actual concentration of the substrate does not reach a reference concentration. For example, the high value of $\alpha(T G)=5$ in equation describing lipolysis in SAWO model (table $V$ ) ensures that lipolysis only occurs when body TG are high. The reasons of a particular value for the sigmoidicity of the reaction are generally not indicated in the description of the models.

However, when comparing the models for a given transaction, some differences do appear: for example, the constant of affinity of $\mathrm{C}_{2}$ units, representing lipogenesis de novo from Ac or Acetyl-CoA, appears to be 10 times more elevated in the GILL1 model than in the
SAWO model. The reasons of these differences are not clear: they could result from different levels of aggregation of the model (if they take into account other substrates or hormonal regulation), or the pools described do not represent the same compartment in the different models. Moreover, differences between species for a particular metabolic pathway may occur: in vitro, it has been recently shown that $A T$ of non lactating, non pregnant ewes appears to be not responsive to insulin alone, whereas AT of cows in same physiological status are responsive (Chilliard and Faulconnier, 1995).

\section{Partition of fluxes: the hormonal regulation}

In the models which take into account hormonal regulation (MARC and SAWO models), this factor is extremely simplified. Hormonal regulation is limited to the concept of an anabolic hormone (AHor) and a catabolic hormone (CHor) as in Baldwin et al (1987). The definition of hormonal status refers to actual Glu concentration compared to reference Glu concentration by:

$$
\text { AHor }=\mathrm{CHor}^{-1}=(\text { Glu/Glu, ref })^{\beta}
$$

Generally in these models, anabolic effects modulate the constant affinity of reactions, whereas catabolic effects affects Vmax; but the reasons for this choice, and the choice of a power $\beta$ (generally 1 or 2 ) are empirical. The main processes that are affected by hormonal status (table VI) are DNA synthesis, lipid, protein and glucose metabolism.

\section{DNA synthesis}

In the MARC model, DNAsyn is regulated by AHor, allowing for variation in the rate of the cell multiplication influenced by nutritional status.

\section{Lipogenesis}

In the MARC model, lipogenesis de novo is affected by AHor at the level of the affinity constant of Glu, but not at the affinity constant for $A C$, nor the Vmax of the reaction. In the SAWO model, inclusion of AHor at the level of $V \max$ and at the constant of affinity for Glu accounts for induction of lipogenic enzymes on one hand, and the increase in sensitivity of AT to Glu on the other hand, when sufficient energy is available. Insulin (INS) in vivo and in vitro has been shown to stimulate activity of AcCoa-Carboxylase and Fatty Acids Synthetase in growing sheep (Vernon et al, 
1991), which are considered as the most limiting enzymes for $\mathrm{Tg}$ synthesis in ruminants. Simultaneously, Glu transport have been shown to be stimulated at the GLUT4 transporter by INS (Abe et al, 1994). The reesterification of plasma $F A$ is regulated only by AHor in the MARC model, by affecting the $\mathrm{K}$ value of Glu (auxiliary substrate of the transaction), because in vivo Broad et al (1983) have shown increased incorporation of Glu into lipid by INS in the sheep. However, in vitro, INS has been shown also to increase activity of total lipoprotein-lipase (Faulconnier et al, 1994), which could suggest that Vmax of the reaction could have been affected by AHor.

\section{Lipolysis}

Lipolysis is affected by $\mathrm{CHor}$ at Vmax for SAWO model, and at the $\mathrm{K}$ constant of plasma FA (inhibitor of the reaction) for MARC model. When insufficient Glu is available, CHor is elevated, which stimulates lipolysis to provide FA; simultaneously AHor is decreased to prevent high lipogenesis from plasma FA to occur, which could illustrate the alternativity of the AT (Chilliard, 1987).

\section{Proteosynthesis}

Only in the SAWO model, Prosyn is regulated by $A H$ or at the $K$ value of $A A$. In the SAWO models, hormonal regulation of Prosyn is not involved.

\section{Proteolysis}

At the contrary of Prosyn, Prodeg is considered only in the MARC model, to be affected at Vmax by $\mathrm{CHor}$, whereas hormonal regulation of these transaction is not included in the SAWO model.

\section{Gluconeogenesis}

Though numerous substrates are precursors of hepatic Glu production, the only one to be affected hormonally is $A A$ by $C H$ or in the MARC and SAWO models. This concept reflects the observation that under low Glu concentration, $\mathrm{CHor}$ is increased which directly stimulates $G N G$, and it increases $A A$ mobilization from body Pro, in order to increase the availability of gluconeogenic precursors (cf above). In vivo, the regulation of GNG from AA have been shown to depend on glucagon and eventually to the permissive effect of glucocorticoides to mobilize body proteins.
Glucose utilization

In the GILL1 model, fractions of NADPH originating from Glu and Acetyl-CoA are fixed to $5 / 6$ and $1 / 6$ respectively. In the MARC model, the fraction of NADPH originating from the degradation of Glu to triose phosphate in adipose tissues is affected by AHor, whereas the fraction originating from isocitrate deshydrogenase via acetate is not regulated. In vivo, G6PDH but not ICDH have been shown to be under INS regulation, at least in the growing sheep (Bas et al, 1995).

\section{Methodological approaches in mechanistic models of growing ruminants}

\section{Language of programation - integration step size}

The step size for numerical integration varies between 0.01 and $1 \mathrm{~d}$ in OLTJ model for a $300 \mathrm{~d}$ simulation, whereas it is between 0.0005 and $0.0002 \mathrm{~d}$ for a $2 \mathrm{~d}$ simulation in the GILL1 model; it is fixed to $1 \mathrm{~d}$ in the SAWO. In the OLTJ model, no effect of the integration step size is detected between 1 and $7 \mathrm{~d}$ if variation in intake is less than 15 and $40 \%$ respectively. The method of integration was a fourth-order Runge-Kutta method, with Advanced Computer Simulation Language (ACSL language).

\section{Internal and external validations}

Internal validation : analysis of sensitivity

The analysis of sensitivity to fixed and estimated constants in the OLTJ model is evaluated by altering them in a range of $\pm 50 \%$ around the value of the constant used in final simulation. In the GILL1 model, the sensitivity of the model is indicated by changing the initial values of pool concentrations, and in the GILL2 model, the analysis of sensitivity is measured by varying the initial protein content in each tissue by $\pm 20 \%$, and its maximal fractional synthetic rate by $\pm 50 \%$.

\section{External validation}

External validation against independent sets of data (data not used for building the model) are performed in OLTJ model, using distinct groups of steers differing in frame size, body composition, feeding regimen, and additive 
(ionophores antibiotics) and hormonal growth promotants. Their validation is based on a set of over 1000 animals containing initial and final empty body weight and composition. By altering the NEg of diets (between 2 and 3 Mcal $E M / \mathrm{kg}$ ), and the proportions (between 0.75 and 1) of energy intake relative to the normal intake, the results on body composition predicted by the model are in good agreement with those observed in practice. They simulate the impact of diet energy concentration, compensatory growth, and effects of feed additives (by increasing KProsyn by $4 \%$ ) and frame size, better than more empirical models. However, fat content of certain breeds (dairy breed) is overpredicted, probably due to increased maintenance requirements (Ferrel and Jenkins, 1984). Further, feed energy available for fat deposition is not used at the same efficiency as for protein gain. More mechanistic representation of maintenance requirements is necessary to increase precision of fat content estimation in their model.

In the FRAN model, where the objectives are to simulate the effects of varying nutrients absorption on energy retention and carcass composition, the model is also validated on an independent set of data. For data where nutrients absorption is measured, the model simulates closely the effect of diet on carcass composition; however, this is not the case when the profile of nutrients absorbed is evaluated from chemical composition of the diet. This shows the need for a simultaneous characterisation of absorbed nutrient profiles and body composition. In the GILL1 model, the validations show that hypotheses tested in the formulation on energy utilisation and efficiency of individual nutrients, are in agreement with observed values when inputs are changed in term of level of energy input, and proportion of energy absorbed from glucose and amino acids. Particularly, it simulates well the decrease in efficiency of energy utilization when level of intake increases, the increase in efficiency when high proportion of energy is absorbed from glucose, and the decrease when the energy originates from $A A$. These results are interpreted in term of different requirements for energy yielding nutrients at different intakes. However, the model points out the lack of data sets giving profiles of absorbed nutrients in relation with experimental determination of energy efficiency and metabolism of individual nutrients.

In the MARC model, validation is made by comparing independent experimental data with the data obtained after simulating heat production after 6 days of fasting, the effects of diet on rate and composition of gain and on efficiency of feed conversion. The model is largely able to simulate compensatory growth, energy retention, heat production and to relate them with energy requirement for metabolic processes. However, the model tends to overpredict performance on high quality diets (and to underpredict them on low quality diets), and the values of parameters for lipogenesis from acetate remain uncertain.

The SAWO model is able to simulate growth and body composition, as well as energy retention (even negative) when level of energy intake and composition of the diets vary, though the efficiency of the simulated diets for growth appears higher than that observed in practice. Particularly, it is able to reflect the observations showing a decrease in fat content in EB gain with increased AA supply, reflecting increase in Pro deposition and in energy expenditure associated with Pro turnover. They simulate rather successfully the effect of different growth promotants ( $\beta$ agonists, anabolic steroids and $\mathrm{GH}$ ) by altering parameters concerning the lipolysis in AT and proteolysis in the body; however their hypothesis are too simple to reflect the multiplicity of modes of action of certain compounds (anabolic steroids).

As in ruminants there is a few data on simultaneous Pro synthesis and Pro accretion on a same diet, the external validation of the model of Gill et al (1989) is made by comparing relationships between $\mathrm{N}$ retention and Pro synthesized, as simulated by the model vs data obtained in pigs. A greater increase in Prosyn/unit increase in $\mathrm{N}$ retained is observed with simulated data, with a greater increase in Pro degradation than in experimental data.

\section{Conclusion}

The mechanistic modelling of animal growth can be made at different levels of aggregation. The optimal level of aggregation doesn't exist per se, but depends on the objectives of the model.

It seems that hormonal regulation of growth needs greater model development. 
Hormonal approaches used in the studied models do preferentially reflect homeostasic regulation, which can be suitable for simulation of metabolism on short periods (some days); it is probably insufficient to reflect homeorhetic regulation, and eventually interrelations between homeostasic and homeorhetic regulations (Weekes, 1986) for several reasons.

Firstly, the phenomenon concerning growth and body composition are under the control of not an only couple of hormones, but of several interacting hormones, including GH (Peel, 1989), insulin-like growth factors (Gluler et al, 1989), thyroid hormones (Spencer 1985), sexual steroids (Schmidely 1992), INS (Weekes, 1986), and glucocorticoides (Sharpe et al, 1986). Secondly, at the metabolic and cellular level, animal of higher genetic merit (leaner animals) are the result of changes in hormone concentrations, numbers of receptors in target tissues, affinity of these receptor, post receptor events (activity of key enzymes), etc. To date, it is clear that insufficient experimental data are available in vivo or in vitro, in order to take into account homeorhetic regulations and to connect them with homeostasic regulations in growing animals. Even in lactating ruminants, where more experimental data are available, these aspects remain essentially theoretical (Sauvant, 1995). Moreover, even when experimental data are available, their validity to represent in vivo fluxes remains questionable, particularly when these data were obtained several years ago (genetic improvement of animals, methodologies in obtaining the data). As a consequence, the fact that short term and long term hormonal regulations are not taken into account, prevents from the possibility of simulating interactions between genotype and nutrition in a short delay of time.

Consequently, experimental programs of research need to be elaborated, and cooperation between nutrition teams and modelling teams need to be developed in order to eliminate these bottlenecks. More mechanistic models must be developed to identify fields of insufficient knowledge, to identify key interactions of metabolism with the aim of manipulating the metabolism for more efficient growth. Finally, an appropriate evaluation of mechanistic growth models is to test them against models used in practice (e.g., INRATION in France) to show their eventual superiority to predict animal performance and to improve nutritional and management practices: this will made later in a further paper.

\section{Literature cited}

Abe $H$, Morimatsu $M$, Aso $H$, Shimizu $Y$, Nikami $H$ Kosaka K. Syuto B, Saito M (1994) Tissue distribution of major insulin responsive glucose transporter (GLUT4) protein in cattle. Proc Soc Nutr Physio/ 3, 214

Bauman DE, Currie WB (1980) Partition of nutrients during pregnancy and lactation: a review of mechanisms involving homeostasis and homeorhesis. J Dairy Sci 63, 1514-1529

Baldwin RL, Black JL (1979) Simulation of the effects of nutritionnal and physiological status on the growth of mammalian tissues: description and evaluation of a computer program. Anim Res $L a b$ Tech, Paper N ${ }^{\circ} 6$, CSIRO, Melbourne, 1-108

Baldwin RL, France J, Gill M (1987) Lactating cow metabolism: 1. Animal elements of a mechanistic model. J Dairy Res 54, 77-105

Baldwin RL, Calvert CC, Hannigan MD, Beckett J (1994) Modelling amino acid metabolism in ruminants. In: Amino Acid in Farm Animal Nutrition (JPF D'Mello, ed) CAB International, Oxon, 281-307

Bas P, Rigaud M, Rouzeau A (1995) Variations nutritionnelles de la capacité lipogénique des tissus adipeux abdominaux chez l'agneau. Ann Zootech 44 suppl, 302

Black JL, Griffiths DA (1975) Effects of liveweight and energy intake on nitrogen balance and total $N$ requirements of lambs. Br J Nutr 33, 399-413

Broad TE, Sedcole JR, Ngan AS (1983) Incorporation of glucose into lipids of perirenal and subcutaneous adipocytes of rat and sheep: influence of insulin. Aust J Biol Sci 36, 147-156

Brodin SV, Yanovich VG (1994) Lipogenic role of aminoacids in muscular and adipose tisues of cattle. Proc Soc Nutr Physio/ 3, 240

Brody S (1945) Bioenergetics and growth, with special reference to the efficiency complex in domestic animals. Reinhold, New York, 180p

Burleigh IG (1980) Growth curves in muscle nucleic acid and protein: problems of interpretation at the level of the muscle cell. In: Growth in Animals, (TJL Lawrence, ed) Butterworths, London, 101-136

Chilliard $Y$ (1987) Revue bibliographique: variations quantitatives et métaboliques des lipides dans les tissus adipeux et le foie au cours du cycle gestation-lactation. 2ème partie: chez la brebis et la vache. Reprod Nutr Develop 27(2A), 327-398

Chilliard $Y$, Faulconnier $Y$ (1995) Insulin and(or) dexamethasone regulation of glucose and 
acetate utilization in ovine and bovine adipose tissues explants incubated for 7 days. J Anim SCi 73, 2063-2070.

Di Marco ON, Baldwin RL (1989) Implementation and evaluation of a steer growth model. Agric Systems 29, 247-265.

Di Marco ON, Balwin RL, Calvert CC (1987) Relative contributions of hyperplasia and hypertrophy to growth in cattle. J Anim Sci 65, 150-157.

Di Marco ON, Balwin RL, Calvert CC (1989) Simulation of DNA protein and fat accretion in growing steers. Agric Systems 29, 21-34.

Faulconnier $\mathrm{Y}$, Thevenet $\mathrm{M}$, Flechet $\mathrm{J}$, Chilliard $\mathrm{Y}$ (1994) Lipoproteine lipase and metabolic activities in incubated bovine adipose explants: effects of insulin, dexamethasone and foetal bovine serum. J Anim Sci 72, 184-191.

France J, Gill M, Thornley JHM, England P (1987) A model of nutrient utilization and body composition in beef cattle. Anim Prod 44, 371- 385.

Ferrel CL, Jenkins TG (1984) Energy utilization by mature, non pregnant, non lactating cows of different types. J Anim Sci 58, 234-243.

Garlick PJ (1980) Protein turnover in the whole animal and specific tissues. In: Comprehensive Biochemistry (Vol 19B) (M Florkin, A Neuberger, LLH van Deena, eds) Elsevier, London, 77-152.

Gill M, Thornley JHM, Black JL, Oldham JD, Beever $D E$ (1984) Simulation of the metabolism of absorbed energy yielding nutrients in young sheep. Br J Nutr 52, 621-649.

Gill M, France J, Summers M, Mc Bride BW, Milligan LP (1989a) Mathematical integration of protein metabolism in growing lambs. J Nutr 119 , 1269-1286.

Gill M, France J, Summers M, Mc Bride BW, Milligan LP (1989b) Simulation of the energy costs associated with protein turnover and $\mathrm{Na}^{+}, \mathrm{K}^{+}$ transport in growing lambs. J Nutr 119, 1287-1299.

Guler HP, Zapf J, Binz K, Froesch ER (1989) Growth promotion using recombinant insulin-like growth factor-1. In: Biotechnology in Growth Regulation. (RB Heap, CG Prosser, GE Lamming, eds) Butterworths, London, 119-122.

Lindsay DB (1976) Amino acids as a source of energy. In: Protein Metabolism and Nutrition. (DJA Cole, KN Boorman, PJ Buttery, D Lewis, RJ Neale, H Swan, eds) Butterworths, London, 183-196.

Lobley GE (1986) The physiological basis of nutrients responses; growth and fattening. Proc Nutr Soc $45,203-214$
Ottjen JW, Bywater AC, Baldwin RL, Garret WN (1986a) Development of a dynamic model of beef cattle growth and composition. J Anim Sci 62 , 86-97.

Oltjen JW, Bywater AC, Baldwin RL (1986b) Evaluation of a model of beef cattle growth and composition. J Anim Sci 62, 98-108.

Peel JM (1989) Growth promoting properties of recombinant growth hormon. In: Biotechnology in Growth Regulation (RB Heap, CG Prosser, GE Lamming, eds) Butterworths, London, 85-96.

Reeds PJ, Wahle KWJ, Haggarthy P (1982) Energy costs of protein and fatty acid synthesis. Proc Nut. Soc 41, 155-159

Sainz RD, Wolff JE (1990a) Development of a dynamic, mechanistic model of lamb metabolism anf growth. Anim Prod 51, 535-549.

Sainz RD, Wolff JE (1990b) Evaluation of hypotheses regarding mechanisms of action of growth promotants and repartitionning agents using a simulation model of lamb metabolism and growth. Anim Prod 51, 551-558.

Sauvant D (1994) Modelling homeostasic and homeorhetic regulations in lactating animals. Livest Prod Sci 39, 105-113.

Sauvant D (1996) A comparative evaluation of models of lactating ruminants. Ann Zootech 45, suppl, 215-235

Schimke RT (1969) Mammalian Protein Metabolism (HN Munro, ed) Academic Press, New-york.

Schmidely $\mathrm{Ph}$ (1993) Revue bibliographique quantitative sur l'utilisation des hormones anabolisantes à action stéroïdienne chez les ruminants en production de viande: 2 . Principaux modes d'action. Reprod Nutr Develop 33, 297-323.

Sharpe PM, Buttery PJ, Haynes NB (1986) Glucocorticoids status and growth. In: Control and Manipulation of Animal Growth (PJ Buttery, NB Haynes, DB Lindsay, eds) Butterworths, London, 207-222.

Spencer GSG (1 985) Hormonal systems regulating growth: a review. Livestock Prod Sci 12, 31-46.

Vernon RG, Barber C, Finley E (1991) Modulation of the activity of acetyl-CoA carboxylase and other lipogenic enzymes by gorowth hormone, insulin and dexamethasone in sheep adipose tissue and relationship to adaptations to lactation. Biochem J 274, 543-548.

Weekes TEC (1986) Insulin and growth. In: Control and Manipulation of Animal Growth (PJ Buttery, NB Haynes, DB Lindsay, eds) Butterworths, London, 187-206 